\title{
Crisis de oportunidad para los jóvenes con escasos estudios en España (2005-2014)
}

\author{
Juan Carlos Solano Lucasi \& Lola Frutos Balibreaii \\ Universidad de Murcia, España
}

\section{Resumen}

La estructura educativa de la población joven en España es única en comparación con otros países de nuestro entorno. Ésta se caracteriza por la polarización del nivel de formación de sus jóvenes. España es el único país de la OCDE con altas tasas, tanto de jóvenes con educación superior, como de jóvenes con un nivel educativo bajo. Nos interrogamos sobre las condiciones educativas y laborales de este colectivo de jóvenes sin estudios obligatorios completados, muy castigados por el contexto de crisis económica. Precariedad, temporalidad, contratos de formación o prácticas, contratos a tiempo parcial se están cronificando en el mercado laboral español, y se están convirtiendo en una norma informal de acceso al empleo y de precarización prolongada del mismo; en parte, a consecuencia de los cambios en las políticas educativas que limitan sus oportunidades de promoción o mejora. Se pretende conocer, a través de los datos de la Encuesta de Población Activa, la situación sociolaboral de los jóvenes con escasos estudios, en un período sumamente convulso: entre el final del boom económico y la crisis económica en España. $Y$ tratamos de interrogarnos hasta qué punto ambas coyunturas socioeconómicas han roto con la igualdad de oportunidades, propiciando la construcción de una sociedad dualizada, desde un punto de vista educativo y laboral.

Palabras-clave

Jóvenes con escasos estudios; Desigualdad de oportunidades; Mercado laboral 


\section{Introducción}

Son muchas las opiniones que señalan la importancia de la educación para obtener mejoras en el mundo laboral, los ingresos, la salud, el capital social e incluso la participación política. $Y$ estas opiniones recorren a perspectivas teóricas diferentes. Desde el pensamiento meritocrático del Capital Humano, Dirk Van Damme, Director del Departamento de Innovación e Indicadores de Progreso de la OCDE, subraya que el rendimiento educativo se relaciona con los resultados económicos y sociales, y la crisis económica ha puesto de manifiesto que el coste social de la crisis, en términos de desempleo y pobreza, ha sido especialmente alto para aquellas personas que carecían de la seguridad que la educación parece garantizar a aquéllos con altos niveles educativos. Pero no sólo afecta a este colectivo, sino a todo el país en el sentido de que las desigualdades educativas pueden llegar a ser disfuncionales a todo el sistema y si los países quieren mejorar de forma sostenible e inclusiva el crecimiento económico y el progreso social deberían, no solo expandir su sistema de educación terciaria sino, además, trabajar en la reducción de la tasa de gente joven con niveles educativos bajos.

En los organismos internacionales como la OECD pesa el enfoque del capital humano: "el mayor rendimiento escolar beneficia tanto a los individuos y la sociedad, no sólo económicamente, sino en el bienestar con el que también se asocia. Para las personas, tener una educación superior mejora las posibilidades de empleo y reduce el riesgo de desempleo" (OECD, 2013, p. 128). Este enfoque otorga una gran relevancia a la elección racional por parte del individuo, cuando la situación de los jóvenes con baja escolarización, sin estudios completos obligatorios, no depende solamente de sus decisiones sino de la estructura social y de la política educativa. Por ello, ignorar a una parte importante de esta población, dejándola sin protección educativa frente a los riesgos de desempleo, precariedad laboral y exclusión social, derivará en una reducción de los avances conseguidos gracias al incremento del rendimiento educativo alcanzado por aquella parte de la población con estudios superiores, además de acentuar la desigualdad social con relación a los que no tienen niveles altos de educación. El progreso educativo debería reflejar una mejora en el conjunto del país.

Nuestro sistema educativo está muy segmentado ya que, por un lado, hay muchos jóvenes con educación terciaria y, por otro, muchos con bajos 
niveles de estudio. Pero también hay otros que no tienen ni estudios obligatorios y hacia ellos orientamos en este estudio preliminar nuestras preguntas de indagación como objetivo básico de investigación. Y ello porque, desde nuestro punto de vista, constituye lo más disfuncional del sistema. Esta línea de investigación llevará a la comparación en el futuro de este colectivo con el resto de jóvenes, pero será abordado en otro trabajo. Así pues, en el estudio que presentamos nos centramos en los jóvenes sin estudios obligatorios completos.

Para abordar este complejo problema, en primer lugar, consideraremos el enfoque teórico y metodológico sobre la juventud y sus decisiones educativas y profesionales teniendo en cuenta la estructura social. Gran parte de los jóvenes que abandonan el sistema escolar de forma tan acusada en España proceden de clases bajas. Frente a un relato acerca de la 'juventud', como si de un grupo homogéneo marcado por la edad biológica se tratara, el análisis sociológico incorpora la clase social, ya que, en realidad, cuando hablamos de jóvenes hablamos de clases sociales.

Nos encontramos con la paradoja de que ninguna sociedad ha rendido un culto tan fanático a la juventud como la nuestra, al tiempo que se excluye a los jóvenes, si bien no de forma homogénea, ya que la peor situación es para quienes carecen de estudios. Hoy más del $40 \%$ de los jóvenes españoles están en paro y los que trabajan lo hacen con contratos precarios y bajos salarios, 6 de cada 10 jóvenes entre 18 y 30 años vive con sus padres y el $55 \%$ depende de ellos, y las perspectivas de mejora en el futuro son escasas.

El relato definido desde los adultos marca los comportamientos deseables y no deseables que la juventud incorpora como propios (Revilla Castro, 2001, p. 114). Pero, junto con ciertos valores considerados como "deseables" se ha llevado a cabo una carga de estereotipos negativos de la juventud y, en cierto grado, se les 'desresponsabiliza' generando la necesidad de que "alguien los cuide", quedando ésta en manos de adultos (Revilla Castro, 2001, p. 108). Además, se considera a la juventud desde "una perspectiva lineal y evolutiva, con un inicio definido en términos negativos y un final en términos positivos" (Benedicto \& López, 2008, p. 16), junto con una perspectiva basada en "lo que puede llegar a ser" (adulto) y no por lo que "es" (joven) (Revilla Castro, 2001, p. 30). 
Desde este marco, el nivel educativo y el rendimiento escolar actúan como legitimación de las posiciones desiguales que se alcanzan. Para quienes no rinden y abandonan la escuela se les señala con un estigma. Así, surge la etiqueta de los 'ninis', que tiene un matiz peyorativo, porque se les imputa a ellos su situación, fenómeno que es internacional. En este sentido, el mismo Banco Mundial les dedica un estudio referido a América Latina (de Hoyos, Halsey, \& Székely, 2016).

Frente a ese relato, lo cierto es que el rendimiento escolar (efecto primario) está muy influido por el origen familiar (efecto secundario), especialmente en el momento de continuar los estudios. La relación entre estudios y trabajo tiene una larga tradición en la sociología de la juventud, constituyendo un marco de referencia para aproximarnos a la realidad de los jóvenes sin estudios obligatorios.

\section{La transición de los jóvenes desde los estudios al trabajo: Marco teórico y estudios previos}

Tanto el enfoque funcionalista como el crítico han explicado la transición de los jóvenes al mercado de trabajo. El primero resalta el paradigma del ciclo vital, al que se añade, a partir de los sesenta, el de la generación y los conflictos que conlleva. El paradigma crítico, más actual, se acerca al individualismo metodológico y a la segmentación social y cultural de los jóvenes para explicar la biografía de estos jóvenes con baja escolarización hacia el mundo del trabajo (Casal, Merino, \& García, 2011). Esta perspectiva nos parece acertada, como señalan Casal, Merino, \& García (2011), como un punto de referencia para abordar la sociología de la juventud que se ocupe de la transición profesional y familiar de los jóvenes. Y ello porque en el contexto de cambios económicos, sociales y culturales influidos por el capitalismo informacional, el enfoque de la transición es interesante considerado como un proceso social (terreno muy propio del constructivismo social), por los constreñimientos sociales (terreno muy propio de las desigualdades) y por su anclaje en lo longitudinal (terreno muy propio de los itinerarios y trayectorias), es decir, por tratarse de una propuesta del individualismo metodológico (Casal et al., 2011, p. 1142).

La sociología de la juventud se ha alimentado en las tres últimas décadas de la perspectiva del ciclo vital y el conflicto entre generaciones. En 
efecto, la distancia generacional entre adultos y jóvenes constituye una constancia histórica que en la actualidad contribuye a generar incomprensión e insolidaridad por parte de los adultos hacia las decisiones que adopta la generación joven (de Zárraga, 1985). Esta cuestión fue resaltada por distintos enfoques: el estructural-funcionalista, a partir del análisis de roles, el enfoque conflictivista de tradición marxista (Allerbeck \& Rosenmayr, 1979), el enfoque biografista basado en los itinerarios y en la segmentación social; autores como Beck (1999), también Baudelot y Establet (2000), Cavalli y Galland (1993), incidieron en la distancia generacional entre jóvenes y adultos.

En la construcción socio-histórica de la juventud es relevante considerar el itinerario-trayectoria de los jóvenes en su transición a la vida adulta, determinados por variables de desigualdad como pueden ser la clase social, el género, la etnia o nacionalidad (Alonso, Martín Criado, \& Moreno Pestaña, 2004; Martín Criado, 2005), más que partir de la consideración de un tramo biográfico desde la pubertad física hasta la emancipación familiar.

Hay factores que condicionan los logros o los fracasos de los jóvenes: el capital cultural institucionalizado, la red de apoyo familiar, las posibilidades y los requerimientos del mercado de trabajo, la coyuntura económica, los procesos de individualización y globalización, etc. Por ello, si bien la juventud, como constructo social, ha sido entendida como una etapa que culminaba con la emancipación o el momento de constitución de nuevos hogares familiares independientes, en la actualidad no sólo no es así, sino que, además, está conformada por factores tanto endógenos como exógenos que determinan su momento de inicio y fin y crean una identidad variable. La experiencia teórica y analítica nos ha mostrado que la juventud se define contextualmente. En la década de los noventa la juventud concluía a los 25 años; sin embargo, hoy seguimos tratando como jóvenes a todos aquellos que no han cumplido los 35 años, edades que en otros tiempos eran consideradas como el momento dorado de la primera madurez.

En los itinerarios y trayectorias de los jóvenes ${ }^{1}$ hay sucesos en la biografía que les sitúan en una posición no ventajosa, como el fracaso escolar básico, o el abandono de la formación sin titulación. Beck (1999) plantea que en la transición hacia la vida adulta hay mucha incertidumbre por lo que muchos jóvenes "deciden no decidir". 
En una sociedad capitalista, basada en la libre elección, la educación adquiere un papel más importante como consecuencia de la exigencia de especialización, así como de los nuevos procesos de actualización de las competencias laborales. Esto conlleva a que los objetivos y las expectativas de los jóvenes actúen como un elemento diferenciador entre generaciones. En este sentido, "la forma desigual en cómo se han producido los sujetos de una y otra generación puede llevar a pensar que los jóvenes actuales pueden aspirar a aquello que su mayor nivel de estudios garantizaba en un estadio anterior, cuando este acceso era impensable por los jóvenes del mismo extracto social en aquel momento" (Brunet \& Pizzi, 2013, p. 28). No obstante, la ausencia de un proyecto educativo personal tiene repercusiones más dramáticas hoy que en el pasado. Ser analfabeto hoy, o no tener estudios obligatorios, es peor que en décadas pasadas.

De las diferentes variables a tener en cuenta para la sociología de la juventud en la transición a la vida adulta es clave analizar la desigualdad de oportunidades; es decir, vincular el proceso individual con las segmentaciones sociales y poderlas explicar y comprender. Los itinerarios y las trayectorias tienen un vínculo con la estructura social: no son independientes de las clases sociales ni del género, ni de la etnia, ni de las migraciones, ni del medio (rural/urbano).

Las teorías de la segmentación del mercado de trabajo (Piore, 1983) identifican situaciones variadas: desde la inserción en trabajos profesionales orientados al éxito social, propios del mercado primario, hasta los poco cualificados y con riesgo de paro y competencia descendente, o trabajos de mercado secundario, e incluso actividades marginales alejadas de las relaciones laborales propiamente dichas. Por tanto, las posiciones sociales adquiridas en la inserción laboral (estratificación) reflejan uno de los puntos importantes de la transición.

En efecto, lo que caracteriza ser joven es el proceso de adquisición profesional y familiar que tiene que ver con el estatus social. Un primer momento lo constituye la transición de la escuela al trabajo, donde son centrales los itinerarios escolares y formativos y las trayectorias; donde 'itinerario' expresa el camino recorrido y 'trayectoria' el futuro anunciado. La escuela, las oportunidades y las disparidades en los itinerarios formativos son clave para el acceso al trabajo. Son buenos indicadores la titulación conseguida, el tiempo escolar invertido y el capital cultural de origen. 
En el inicio de los itinerarios laborales ocurre lo mismo; en primer lugar, el joven, con su nivel de estudio alcanzado, se encuentra ante el mercado de trabajo y tiene que tomar decisiones que están determinadas por las oportunidades de empleo, la generación y el horizonte profesional de clase. Algunos itinerarios laborales auguran una trayectoria fallida que define un campo para el desarrollo de políticas de inserción contra la exclusión social. En efecto, el acceso al mercado del trabajo y las condiciones en las que se produce supone un punto de inflexión importante en las vidas de los jóvenes por dos razones. En primer lugar, y conectado con el capital cultural institucionalizado desde un enfoque longitudinal puede representar una continuidad respecto a los logros alcanzados en el sistema educativo. En segundo lugar, el acceso al mercado del trabajo, atravesado trasversalmente por variables socioeconómicas, como edad, género, condiciones laborales y sector de actividad, etc., puede condicionar tanto trayectorias laborales presentes como futuras. Más aún, el joven que accede al empleo puede encontrarse con: 1) empleos que no requieren una cualificación previa en el mercado de trabajo; 2) empleos a los que se accede según los requerimientos del mercado de trabajo (desde una perspectiva coyuntural) no determinados por una cualificación previa aunque sí se exija para mejorar la productividad; y 3 ) empleos que requieren una cualificación profesional específica. Todo ello puede determinar sus oportunidades laborales y sociales.

Aunque tenemos en España la generación con mayor formación, muchos jóvenes acceden al mercado de trabajo a puestos donde no existe una conexión entre formación, contratación y condiciones laborales. La actual coyuntura económica (crisis económica, reforma laboral, flexibilidad del mercado de trabajo, etc.) favorece situaciones de vulnerabilidad laboral que muchos jóvenes viven independientemente del logro alcanzado en el sistema educativo. Pero peor es la situación de aquellos jóvenes que no han concluido sus estudios.

Casal, García, Merino, y Quesada (2007) señalan las posiciones conseguidas por los jóvenes a largo plazo en la inserción profesional y anuncian varios futuros diferentes donde se da una segmentación social fuerte vinculada a las clases y a las desigualdades ${ }^{2}$.

Hay autores que demuestran en estudios con base empírica que el rendimiento bajo escolar no es interpretado de la misma forma por los 
individuos de distinto origen social, ya que existe una compensación en los estudiantes de clase alta al tener más posibilidades de seguir estudiando Educación Secundaria Superior o Universitaria, a pesar de que sus notas sean bajas (Bernardi \& Cebolla, 2014). Aunque la máxima desigualdad se daría en los peores estudiantes de clase baja.

Como señalan estudios previos, España se caracteriza por haber logrado una mediana movilidad de renta desde una alta desigualdad social y desde un sistema escolar equitativo (Martínez Celorrio, 2013, p. 34), pero la prevalencia que juegan los recursos clasistas es más fuerte en España - con un índice de Gini superior a 30 -que en otros países.

Entre 1985-2000 España desarrolla sus políticas de bienestar, los cambios postindustriales que elevan el umbral educativo de entrada en el mercado de trabajo y la democratización de acceso a los grados superiores. Durante ese periodo se reduce la desigualdad de oportunidades que se sitúa en la media europea UE-25, pero contrasta con la más intensa reducción registrada en Portugal y Polonia, países de tradición católica y de escolarización tardía como España, aunque partían de un mayor nivel extremo de desigualdad.

En el plano educativo, en 1985 se alcanzó por primera vez en la historia de España la escolarización del 100\% de los jóvenes en edad de estar en el sistema educativo. No obstante, la presión demográfica del baby boom español, junto con la tradición católica, llevó a las autoridades políticas a crear una singularidad dentro del panorama internacional en lo que se refiere a su red de centros educativos sostenidos con fondos públicos. Dicha singularidad estriba en la figura de los centros concertados, una mixtura jurídica entre su titularidad privada y la financiación pública que reciben a través de las subvenciones (conciertos), a cambio del sometimiento a las normas generales (Fernández \& Muñiz, 2012, pp. 97-98).

Conviene recordar que la Constitución de 1978 proclamó el derecho a la educación y la libertad de enseñanza. Se introdujo la gratuidad y la obligatoriedad. La Constitución no ampara el derecho a la subvención de los centros privados a cargo del gasto público. Sin embargo, el establecimiento de la LODE, en 1985, categorizó: centros públicos, privados y privados concertados. La LOGSE de 1996, que suponía un avance sin precedentes en el derecho a la educación - acorde con la Constitución y la LODE -, amplió la 
escolarización obligatoria hasta los 16 años y redujo el número de alumnos por aula de 40 a 25 alumnos, razones que abrían aún más la posibilidad de ampliar los convenios con los centros privados a través de los conciertos. Así, el proceso de privatización de la enseñanza en España se demuestra a través del incremento de los centros privados y privados concertados entre 1990 y 2015. Según datos de la "Estadística de las Enseñanzas no universitarias" ofrecidos a través de la Subdirección General de Estadística y Estudios del Ministerio de Educación, Cultura y Deporte, entre esas fechas se ha producido un incremento en los centros de Educación Infantil y Educación Primaria de un 4,1\%; sin embargo, dicho incremento se reparte de manera desigual: mientras que los centros educativos públicos sólo han crecido un 0,9\%, los centros privados y privados concertados lo han hecho en un $11 \%$.

Las autoridades justifican los convenios como respuesta a la demanda de las familias, que buscan en ellos una calidad al margen de la pública. Sin embargo, todos los estudios sociológicos señalan que lo determinante en el resultado escolar del alumnado no es la titularidad del centro, sino el capital cultural de la familia de la que procede. El estudio de Fernández y Muñiz (2012), con base empírica, a partir de la explotación del Estudio del Centro de Investigaciones Sociológicas - CIS (2006), demuestra que el argumento básico para las familias no es una mayor calidad educativa, sino que la demanda está en función de las características socioeconómicas del alumnado en las escuelas concertadas, significativamente distintas a las de los centros públicos. A pesar de que el acceso a los centros concertados sea similar formalmente a los públicos, en los primeros se concentran familias con ingresos medios y altos y niveles de estudios elevados (Escardibul \& Villarroya, 2009), así como de origen nacional (Salinas \& Santín, 2012). Este fenómeno produce que España sea uno de los países de la OECD con mayor concentración de alumnado con el mismo origen social en los colegios, así como el país en el que el tipo de centro (público o privado) influye más en la segregación social (Jenkins, Micklewright, \& Schnepf, 2006). Las barreras de acceso para elegir centro impiden el paso a determinados grupos, exclusión que, como ya señalara Parkin (1984), es muy acusada en los denominados centros gueto (Fernández Enguita, Mena Martínez, \& Riviere Gómez, 2010). Serían aquellos que contienen una elevada proporción de alumnos con recursos escasos y de origen inmigrante. De continuar así, España se 
abocará aún más a la disminución de la equidad y de la igualdad de oportunidades. Este proceso de privatización de la educación, entre otras consecuencias, trae consigo la polarización de la pirámide educativa y también su reflejo en el mercado laboral.

La expansión de la educación educativa no reduce el diferencial de los hijos de las clases superiores, manteniendo constantes sus ventajas relativas sobre las clases inferiores, por mucho que éstas se beneficien de la democratización de accesos (Raftery \& Hout, 1993). España ha pasado de un $16 \%$ de hijos con padres de educación básica que logra titulaciones superiores terciarias en los nacidos entre 1950-59 a un 33\% entre los nacidos entre 1970-79 con el mismo origen social. Mientras, hemos pasado de $69 \%$ a un $73 \%$ de herencia de la educación superior o terciaria entre padres e hijos en estos últimos 20 años. Por ello, la odd ratio de ventaja o desventaja relativa entre ambos orígenes educativos se sitúa en el 2,3 en la cohorte joven nacida entre 1970-79. Se trata todavía de un diferencial significativo que discrimina a los hijos con padres de bajo nivel educativo en las oportunidades de titularse en la educación superior o terciaria (Martínez Celorrio, 2013, p. 36). Según datos analizados por estos autores, a partir de la encuesta del CIS sobre Clases Sociales y Estructura Social (Centro de Investigaciones Sociológicas, 2006), resulta preocupante el repunte de la herencia obrera en la cohorte nacida entre 1972-76 apuntalado por la mayor presencia de mano de obra inmigrante con orígenes también obreros y populares.

A conclusiones parecidas llegan Martínez García y Fernández Mellizo (2015) en su explotación de la EPA, referida al $2^{\circ}$ trimestre de 2012. En sus análisis consideran la tasa de fracaso escolar entre 19-20 años por cohorte de nacimiento y clase social. Las tasas de fracaso escolar de los hijos de Clase de Servicio nacidos entre 1957-60 suponen un 14,8\%; las de las Clases Intermedias, un 34,8\%; las de los Pequeños Propietarios, 36,8\%; las de la Clase Obrera asciende a un 58,9\%; y las de la Clase Agraria a un 69,1\%. La transformación, pasados 36 años, ha supuesto una disminución del fracaso escolar generalizado, ya que globalmente en los nacidos entre 1957-60 era de un 50\% y en los que nacieron entre 1993-94 las tasas de fracaso escolar son de un 15,9\%. Ahora bien, percibimos el mantenimiento de la reproducción social en el hecho de que la Clase de Servicio presenta una tasa de fracaso en los nacidos entre 1993-94 sólo de un 3,6\% frente a un $27,6 \%$ de las Clases 
Agrarias y un $15,7 \%$ de la Clase Obrera. Las Clases Intermedias presentan tasas muy elevadas, de un 16,9\%, y los Pequeños Propietarios de un $14,4 \%$.

Martínez García y Fernández Mellizo (2015) calculan la tasa de fracaso escolar de los nacidos en el extranjero y de los extranjeros de 19 a 20 años teniendo en cuenta el sexo y la nacionalidad: las disparidades son evidentes, pues en España, en 2012, la tasa de fracaso escolar era de 14,3\% (17,7\% en los hombres y $10,6 \%$ en las mujeres); sin embargo, la incidencia es menor entre asiáticos (11,4\% la tasa total - 13,6\% en hombres y sólo 9,6\% en mujeres). También es menor la tasa de fracaso entre los nacidos en la Europa desarrollada, América del Norte y Oceanía desarrollada (9,3\% la tasa total y por sexo, $8 \%$ en varones y $10,4 \%$ en mujeres). Las tasas de fracaso escolar más elevadas corresponden a los nacidos en África $(51,3 \%$, siendo en el caso de los hombres un $53,7 \%$ y en el de las mujeres un $49,2 \%$ ). Los procedentes de América Latina también tienen cifras superiores de fracaso escolar que España: $19,8 \%$ (20,1\% en el caso de los varones y $19,5 \%$ en el de las mujeres). Este fenómeno también tiene relación con el mercado de trabajo, ya que si la discriminación dificulta el acceso a puestos que requieren titulación académica, los inmigrantes no apuestan por el éxito educativo. En cualquier caso, como han señalado Aparicio y Portes (2014), el proceso de asimilación de inmigrantes es bastante igualitario, aunque con una asimilación segmentada.

\section{Evolución del nivel educativo alcanzado en España}

Es un hecho que España es el único país de la OCDE con altas tasas de jóvenes con educación superior y de jóvenes con bajo nivel educativo. Desde la década de los noventa se ha transformado la estructura del nivel educativo de la población (Gráfico 1); pero no se han producido avances significativos en los niveles intermedios. Hemos avanzado mucho en materia de educación superior, hasta el punto que podemos arriesgarnos a decir que es el único objetivo de la Europa 2020 que ya hemos alcanzado. También hemos reducido el número de jóvenes con escasa escolarización; sin embargo, no hemos conseguido mejorar sustancialmente la educación secundaria superior y postsecundaria, al mismo tiempo que llevamos ya poco más de una década con porcentajes estables en la categoría de jóvenes con bajos estudios (secundaria inferior o menos). A mediados de la década de los 
noventa se alcanzaron los 1,5 millones de jóvenes realizando estudios superiores, y en 2009 se consiguió invertir el 5,1\% del PIB en educación.

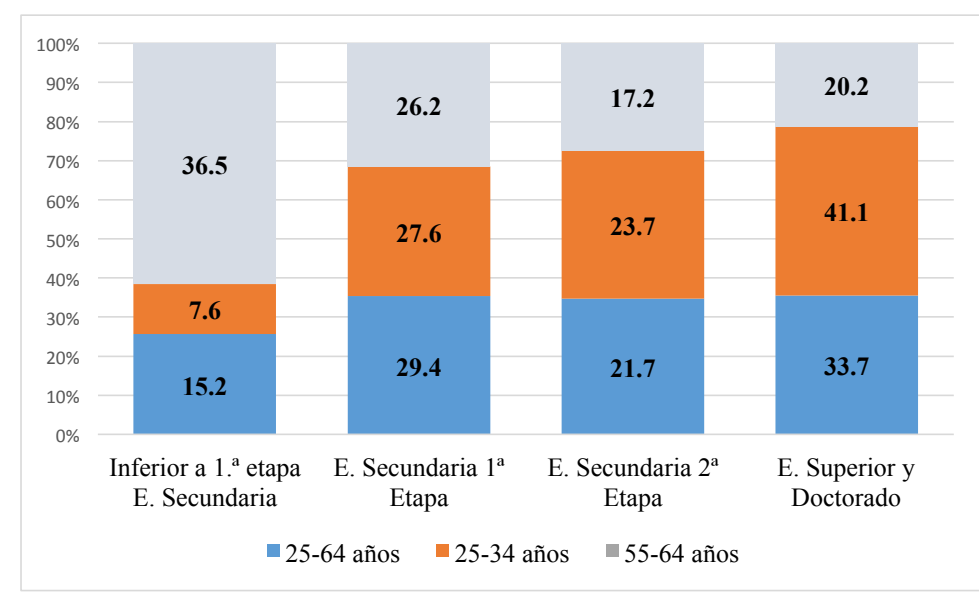

[Fuente: MEC (2015), Las cifras de la educación en España. Datos e Indicadores Curso 2012-2013 (Indicador A1.2)]

\section{Gráfico 1 - Nivel educativo adquirido por la población adulta en} España, 2013

El nivel educativo adquirido por la población en España es muy diferente según la estructura de edad. En efecto, observamos en el Gráfico 2 los cambios educativos operados en los distintos grupos etarios en nuestro país a través del tiempo: cuatro de cada diez personas entre 25-34 años cuenta con Educación Superior y Doctorado, mientras que en el grupo de edad 55-64 es justo la mitad. Es destacable que un 27,6\% de los jóvenes que se encuentran entre los 25-34 años sólo ha alcanzado la $1^{\text {a }}$ etapa de Secundaria. 


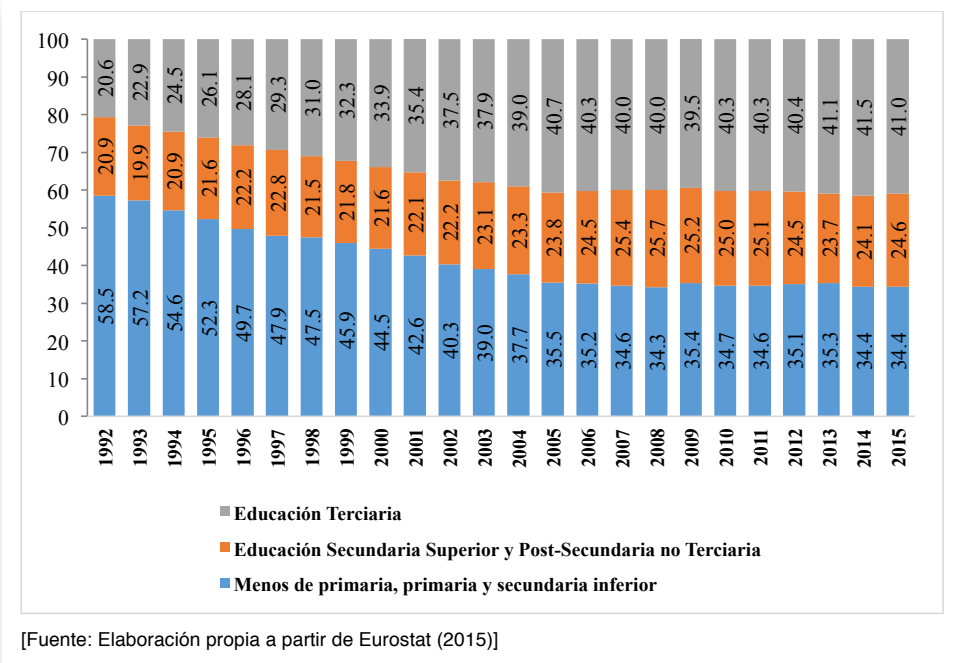

Gráfico 2 - Evolución del nivel educativo de la población entre 25 y 34 años. España, 1992-2015

¿Hacia dónde vamos? Las respuestas no son muy claras porque quedan al albur de las decisiones y las estrategias políticas, así como de las necesarias inversiones para llegar a los objetivos que diseñen las nuevas leyes educativas del gobierno de turno. Pero, obviamente, si prosigue la tendencia de mercantilización de la educación (fomento de la financiación pública de centros privados, segregación educativa por clase y sexo, evaluaciones externas y rankings de centros, etc.), el incremento de la polarización de la educación en España será una realidad mayor.

Por otro lado, tiende a ajustarse cada vez más a una estructura del mercado laboral también más polarizada. Además, encaja perfectamente con lo planteado por Piore (1983), o lo que apuntaba Tezanos (2001) a principios de la década pasada: "la reducción de puestos de trabajo disponibles, sobre todo los puestos de cierta calidad y nivel, da lugar a una alteración sustantiva del carácter ubicador que el trabajo tenía en las sociedades industriales" ( $p$. 161). 
La distribución del desempleo dentro de la generación más joven arroja luz sobre algunos de los factores que pueden aumentar el riesgo de la falta de trabajo, la cual, a su vez, ofrece una visión de las respuestas políticas. En particular, el logro educativo tiene un enorme impacto en la empleabilidad, y la crisis ha reforzado aún más este impacto (OECD, 2013 p. 15).

Antes de valorar el impacto de la crisis en los jóvenes sin estudios, vamos a realizar una reflexión sobre el contexto de los ajustes entre los jóvenes titulados entre 25-29 años y las categorías ocupacionales conseguidas en el mercado de trabajo, a partir de los datos de la EPA y referidos al año 2013 (Tabla 1). ¿Por qué seleccionamos esta cohorte demográfica? Para establecer un marco de referencia con respecto a los jóvenes sin estudios obligatorios. Representa una foto fija que nos permite contrastar los cambios que les afectan, y sus condiciones socioeducativas causadas por la crisis.

En el año 2013, tras cinco años de crisis económica, la tasa de no ocupados se nutre de los diversos niveles educativos, pero como podemos apreciar son fundamentalmente los más bajos los que presentan porcentajes más elevados (Tabla 1). Con estudios primarios o menos, casi un $52 \%$ de jóvenes entre 25-29 años está en paro, mientras que para los universitarios es inferior al $20 \%$. En cuanto a las ocupaciones que consiguen estos jóvenes con menos de estudios primarios, suponen casi un $14 \%$ en las categorías de trabajador no cualificado y cualificado de la industria y los servicios. El paro para los que realizaron estudios de primera etapa de secundaria sin título supone un $35,8 \%$, y las categorías ocupaciones que alcanzan son las de trabajadores cualificados y no cualificados $(17,2 \%)$. 


\begin{tabular}{|c|c|c|c|c|c|c|c|c|}
\hline & 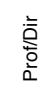 & 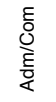 & 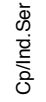 & ○ & $\begin{array}{l}\text { రृ } \\
\dot{\bar{\sigma}} \\
\bar{J}\end{array}$ & 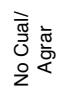 & 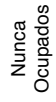 & 뜽 \\
\hline $\begin{array}{l}\text { PRIMARIOS O } \\
\text { MENOS }\end{array}$ & 0,2 & 4,4 & 4,2 & 12,3 & 13,4 & 13,6 & 51,9 & 9.9 \\
\hline $\begin{array}{l}\text { 1ASec. INF SIN } \\
\text { TÍTULO }\end{array}$ & 1,0 & 8,4 & 6,9 & 13,6 & 17,2 & 17,2 & 35,8 & 5,5 \\
\hline $\begin{array}{l}\text { 1BSec. INF SIN } \\
\text { TÍTULO }\end{array}$ & 1,2 & 15,2 & 5,5 & 18,9 & 18,1 & 10,4 & 30,6 & 26,5 \\
\hline 1C FP1-CMED & 4,3 & 20,8 & 6,8 & 24,8 & 16,9 & 6,5 & 19,9 & 11,7 \\
\hline 2B BACHILLERATO & 3,9 & 19,3 & 3,9 & 30,5 & 10,2 & 6,9 & 25,3 & 11,1 \\
\hline $2^{\mathrm{a}}$ FP2 CSUP & 20,7 & 23,7 & 6,5 & 14,8 & 13,9 & 3,6 & 16,9 & 11,3 \\
\hline $3^{\mathrm{a}}$ UNI1 & 49,7 & 17,9 & 1,9 & 9,3 & 2,6 & 1,6 & 16,9 & 10,5 \\
\hline $3 \mathrm{~B}$ UNI2-3 & 57,1 & 15,8 & 1,9 & 5,7 & 0,3 & 0,6 & 18,6 & 13,4 \\
\hline $\begin{array}{l}\text { TOTAL } \\
\text { (N) }\end{array}$ & 16,6 & 16,2 & 4,7 & 16,7 & 12,1 & 7,2 & 26,6 & $\begin{array}{c}100 \\
(8.655)\end{array}$ \\
\hline
\end{tabular}

Tabla 1 - Nivel de estudios y categoría profesional alcanzada por los jóvenes entre 25-29 años en España, 2013 (\%)

Los jóvenes con la segunda etapa de secundaria sin título presentan un $30,6 \%$ de paro, mientras que el porcentaje más alto de ocupados se ubica en la categoría de otros servicios (18,9\%) y en la de trabajadores cualificados $(18,1 \%)$. Los jóvenes con Formación Profesional 1 (FP1) presentan un paro más reducido $(19,9 \%)$ y la categoría ocupacional donde más representados están es en otros servicios (24,8\%), seguida de la de administrativo (20,8\%). Llama la atención que los jóvenes con bachillerato presentan un paro mayor $(25,3 \%)$, lo que remarca la idea de que estos estudios no están orientados hacia el mercado de trabajo, sino que están pensados para continuar estudiando otros niveles educativos superiores. Un 30,5\% están ocupados en otros servicios. Los niveles de paro más bajo corresponden a los estudios de FP2 y primer nivel universitario (16,9\%). Estos últimos alcanzan - en un $49,7 \%$ - la categoría ocupacional más elevada - profesionales y directivos -, mientras que los que cuentan con FP2 suponen en esa categoría un 20,7\%. Los que cuentan con el nivel superior de estudios universitarios presentan un paro más elevado (18,6\%), pero un $57,1 \%$ se ocupan en la categoría más elevada (profesionales y directivos).

Analizado este contexto, nuestro objetivo empírico son los jóvenes sin estudios obligatorios. 


\section{Aproximación a la realidad de los datos de los jóvenes sin estudios. El perfil de los jóvenes sin estudios completos obligatorios}

¿Cómo son los jóvenes sin estudios obligatorios terminados? Uno de los conceptos más utilizados para tratar la problemática de estos jóvenes es el concepto de abandono educativo temprano, y se trata de una convención internacional referida al porcentaje de jóvenes de 18 a 24 años que ha alcanzado como máximo la Educación Secundaria primera etapa (obligatoria) y no continúan estudiando o formándose a fin de alcanzar el nivel que para el siglo $\mathrm{XXI}$ se ha definido como deseable.

El debate en torno al abandono educativo temprano ha sido muy interesante y rico. Al mismo tiempo, existe cierta controversia por su utilización, en la medida que fomenta la estigmatización de las personas con escasa escolarización; incluso se ha dicho que, estructuralmente, las diferencias entre países se deben "a distintas tradiciones socioculturales y percepciones, diversas estructuras de los sistemas de educación y formación y de la economía y el mercado laboral, a las reformas aplicadas, al grado de participación de los interlocutores sociales, a las perspectivas de empleo de los titulados en EFP y a las preferencias individuales", según afirma la Comisión Europea (2012, p. 6), poniendo así en duda parte de la propia eficiencia del concepto.

No obstante, la decisión de abandonar está afectada por numerosos factores en función de los costes o beneficios que el sujeto espera conseguir con la inversión educativa, tal y como analiza Boudon (1983) al distinguir entre los efectos primarios y los secundarios. O, como Dustmann (2004) demuestra, la importancia de las características y condiciones socioeconómicas de las familias. O las consecuencias del abandono educativo temprano en las probabilidades de encontrarse en situación de exclusión social (Solano, 2008). Sin olvidar la importancia de los factores de entorno determinantes de la estructura económica, especialmente la intensificación de mano de obra poco cualificada en el sector de la construcción (Aparicio Fenoll, 2010).

Si bien hay controversia sobre el concepto, lo cierto es que todas aquellas personas que abandonan los estudios tienen tasas de empleo inferiores a los que han superado este nivel educativo y que, en cualquier 
caso, se van a enfrentar a grandes dificultades para permanecer en el mercado laboral; y, si lo hacen, lo harán con salarios bajos y alto riesgo de precariedad y pobreza. Lo que, a la larga, supone para la sociedad un empeoramiento de su bienestar, en la medida en que habrá menores tasas de actividad, empleo y productividad (Serrano, Soler, Hernández, \& Sabater, 2013).

Uno de los retos fijados por la Comisión Europea dentro de la estrategia 2020 es reducir la tasa de abandono escolar a menos del 10\% y aumentar hasta al menos el $40 \%$ la tasa de titulados de la enseñanza superior. Este último indicador ya hace tiempo que se alcanzó en España, pero no es menos cierto que reducir el abandono escolar prematuro sigue siendo una tarea pendiente y preocupante. No sólo porque sea un objetivo a alcanzar para el Horizonte 2020, sino porque es una forma de conseguir una sociedad más justa, y con proyección de futuro. Los datos así lo demuestran. Recordemos que el nivel educativo de los padres es un factor de importancia en el abandono, y muy especialmente el nivel formativo de la madre (Instituto Nacional de Evaluación Educativa, 2015). De hecho, en el año 2014, el abandono escolar de aquéllos jóvenes cuya madre tiene estudios superiores únicamente es del 3,7\%, y del $11,4 \%$ si tienen segunda etapa secundaria, hasta alcanzar valores por encima de la media cuando tiene primera etapa de secundaria, 23,1\%, y 41,1\% para educación primaria o inferior. Este es un hecho que se viene repitiendo en la historia reciente.

¿Pero quiénes son los jóvenes sin estudios obligatorios terminados? Son personas entre 16 y 29 años que no han alcanzado la segunda etapa de la enseñanza secundaria, y no realizan ningún tipo de formación (reglada o no reglada). Este colectivo representa entre el $23 \%$ y el 29,2\% de los jóvenes de España, entre 2005 y 2014, respectivamente (Gráfico 3). Desde 2006, tanto el número como el porcentaje de jóvenes sin estudios obligatorios terminados han ido descendiendo; sin embargo, no lo han hecho con la misma intensidad en términos relativos. Si bien es cierto que el porcentaje de jóvenes sin estudios se ha reducido en 6,2 puntos porcentuales en este periodo de tiempo, no es menos cierto que la reducción del volumen de población ha sido más intensa. En 2005 la población joven de entre 16 y 29 años era de poco más de 8,5 millones de efectivos, que representaban el $19,6 \%$ de la población total. Diez años más tarde, en 2014 , dicho volumen de población se redujo un 
$27,7 \%$, representando un total de poco más de 6,6 millones de jóvenes - es decir, un $14,9 \%$ del total de la población española ${ }^{3}$. En términos absolutos, el descenso del número de jóvenes sin estudios fue muy intenso, pasando de 2,44 millones en 2005, a 1,53 millones en 2014, lo que representa una caída del $59,6 \%$.

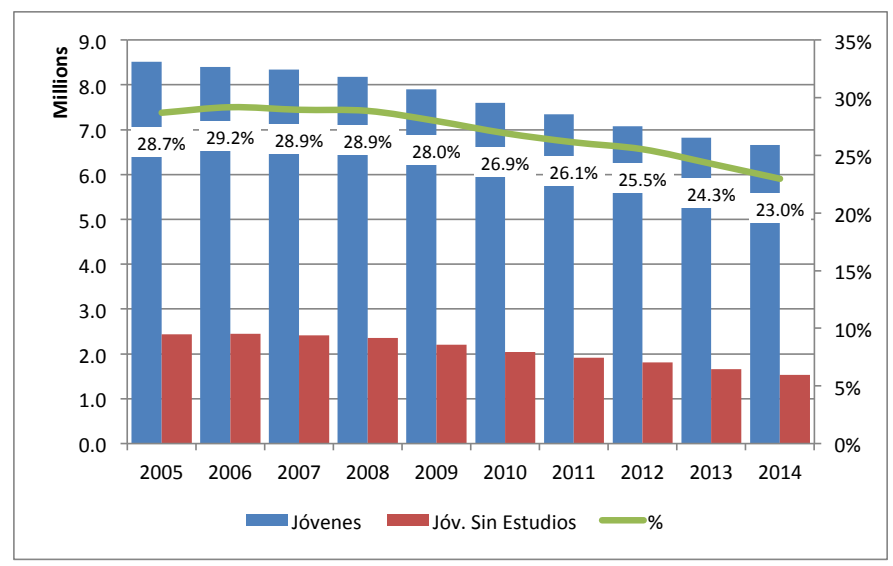

[Fuente: INE, www.ine.es EPA. Elaboración propia]

\section{Gráfico 3 - Número de jóvenes y jóvenes sin estudios obligatorios, y porcentaje de jóvenes sin estudios obligatorios terminados con respecto al total de jóvenes. España, 2005-2014}

Como podemos ver, parte de dicho descenso que se manifiesta en el porcentaje de jóvenes sin estudios se debe a un efecto estadístico que esconde una reducción muy importante del volumen de personas en estas edades. Este hecho no es achacable a un supuesto impacto de la inmigración a consecuencia del retorno, ya que a lo largo de este período de análisis se observa una relativa estabilidad en el porcentaje de jóvenes extranjeros, que ronda por término medio el $16 \%$. Aunque no podemos descartar que algo de esta reducción se haya producido gracias a las nacionalizaciones de jóvenes extranjeros, las cuales se han intensificado en los últimos años. 
En la actualidad se observa una tendencia al "envejecimiento" de la juventud. Es decir, la cohorte de 25 a 29 es cada vez más numerosa en términos relativos, mientras que la cohorte de 16 a 19 años tiene menos peso en el colectivo, lo que demuestra que no se están produciendo de manera significativa aportaciones de efectivos de población en estas edades, ni desde la base (nacimientos), ni desde el exterior (inmigración) (Tabla 2).

\begin{tabular}{|l|c|c|c|c|c|c|c|c|c|c|}
\cline { 2 - 11 } \multicolumn{1}{c|}{} & 2005 & 2006 & 2007 & 2008 & 2009 & 2010 & 2011 & 2012 & 2013 & 2014 \\
\hline \multirow{2}{*}{$\begin{array}{l}\text { de 16 a 19 años } \\
\text { de 20 a 24 años } \\
\text { de 25 a 29 años }\end{array}$} & 15,7 & 16,6 & 16,1 & 15,9 & 14,0 & 12,1 & 11,2 & 11,5 & 11,6 & 10,2 \\
\cline { 2 - 10 }$y$ & 36,7 & 36,0 & 35,8 & 38,2 & 36,9 & 36,9 & 35,9 & 36,4 & 34,9 & 35,5 \\
\hline & $100 \%$ & $100 \%$ & $100 \%$ & $100 \%$ & $100 \%$ & $100 \%$ & $100 \%$ & $100 \%$ & $100 \%$ & $100 \%$ \\
\hline
\end{tabular}

Tabla 2 - Jóvenes sin estudios obligatorios terminados por grupos de edad (\%). España, 2005-2014

Más de la mitad de los jóvenes sin estudios obligatorios terminados son hombres, valores que han rondado entre el $58,9 \%$ de 2014 y el $61,7 \%$ de 2006. Como podemos apreciar en el Tabla 3, se ha reducido la brecha entre hombres y mujeres en este período de tiempo, a consecuencia de que la disminución en valores absolutos del número de hombres, que engrosa esta categoría, ha sido sustancialmente mayor que entre las mujeres. Esta disparidad entre hombres y mujeres tiene su sentido en la medida en que, históricamente (al menos en la España moderna), el abandono educativo temprano ha sido protagonizado por la población masculina, llegando, en el año 2009 , a que la brecha entre hombres y mujeres fuera de un $51 \%$, más alta en los hombres que en las mujeres (Instituto Nacional de Evaluación Educativa, 2015).

\begin{tabular}{|l|c|c|c|c|c|c|c|c|c|c|}
\hline & 2005 & 2006 & 2007 & 2008 & 2009 & 2010 & 2011 & 2012 & 2013 & 2014 \\
\hline Hombre & 61,5 & 61,7 & 60,1 & 61,6 & 60,8 & 59,6 & 59,8 & 59,1 & 59,2 & 58,9 \\
\hline Mujer & 38,5 & 38,3 & 39,9 & 38,4 & 39,2 & 40,4 & 40,2 & 40,9 & 40,8 & 41,1 \\
\hline Total & 100 & 100 & 100 & 100 & 100 & 100 & 100 & 100 & 100 & 100 \\
\hline
\end{tabular}

Tabla 3 - Jóvenes sin estudios obligatorios terminados, por sexo (\%) España, 2005-2014 
Como hemos dicho antes, la población joven extranjera ha ido descendiendo tanto en términos relativos, como absolutos, a lo largo de esta década. Sabemos que una parte de este colectivo ha engrosado las listas de los españoles y de los españoles con doble nacionalidad, lo que significa una reducción de los efectivos de extranjeros y al mismo tiempo un incremento del peso de los jóvenes con nacionalidad española. En realidad los cambios no han sido muchos, más de ocho de cada diez jóvenes tienen la nacionalidad española. Pero las cosas cambian cuando observamos el peso relativo que tienen los extranjeros dentro del colectivo de jóvenes sin estudios en España. Tal y como podemos ver en el tabla 4 - referido a los jóvenes extranjeros sin estudios del total de jóvenes sin estudios, por sexo, 2005-2014 -, los jóvenes extranjeros representan entre una quinta y una cuarta parte del total de jóvenes sin estudios. Esto nos hace pensar que el modelo de inserción social español (si lo hubiese) ha fracasado, en la medida que los jóvenes extranjeros no han podido aprovechar las supuestas oportunidades que brinda el estado social para mejorar o ampliar su cualificación y elevar su nivel de oportunidades. Si bien ya vimos en los datos secundarios que hay diferencias por nacionalidades en lo referente al fracaso escolar, no sabemos hasta qué punto este hecho se debe a una intensificación de la reproducción social de la estructura social, es decir, a la influencia del nivel sociocultural y económico de la familia de origen, más bajo que el de la población autóctona.

Por último, no podemos dejar de destacar cómo el perfil del joven extranjero sin estudios es eminentemente femenino. Como podemos ver en el siguiente tabla (Tabla 4), los porcentajes de personas sin estudios son mayores en el caso de las mujeres que en el de los hombres de origen extranjero, en contraposición al perfil marcadamente masculino de los jóvenes sin estudios de nacionalidad española 4 . Esto demuestra que no sólo ha fallado el modelo de inserción de la inmigración, sino también el modelo de autonomía personal e igualitaria que supuestamente contempla el sistema educativo español, ya que los datos nos sugieren la supervivencia de un modelo patriarcal más acentuado, incluso, que el existente en las familias españolas. El patriarcado se apoya en el consenso en torno a la socialización de género. La decisión de emigrar, de estudiar, de trabajar, para muchas jóvenes, en muchos casos, no nace de ellas mismas, sino que sigue un patrón de género. Muchas mujeres adoptan sus decisiones en función de su núcleo 
familiar y ellas mismas constituyen un factor de reajuste y acomodación al sistema económico. La interiorización de los principios patriarcales (dominio del varón sobre la mujer y del varón sobre los jóvenes) impide la autoestima de las mujeres para emprender estudios que les suponga una movilidad social ascendente y son las propias mujeres las que se subestiman y se inhiben, a pesar del reconocimiento de equidad educativa existente en España. Por último, no podemos dejar de destacar cómo el perfil del joven extranjero sin estudios es eminentemente femenino (Tabla 5).

\begin{tabular}{|l|c|c|c|c|c|c|c|c|c|c|}
\hline & 2005 & 2006 & 2007 & 2008 & 2009 & 2010 & 2011 & 2012 & 2013 & 2014 \\
\hline Hombre & 17,2 & 19,7 & 20,4 & 22,0 & 23,4 & 19,7 & 19,5 & 20,9 & 19,8 & 18,4 \\
\hline Mujer & 22,1 & 24,9 & 29,8 & 29,4 & 27,5 & 30,1 & 30,1 & 31,4 & 27,3 & 28,1 \\
\hline Total & 19,1 & 21,7 & 24,1 & 24,9 & 25,0 & 23,9 & 23,7 & 25,2 & 22,9 & 22,4 \\
\hline
\end{tabular}

Tabla 4 - Jóvenes extranjeros sin estudios obligatorios terminados del total de jóvenes sin estudios obligatorios terminados, por sexo (\%). España, 2005-2014

\begin{tabular}{|l|c|c|c|c|c|c|c|c|c|c|}
\hline & 2005 & 2006 & 2007 & 2008 & 2009 & 2010 & 2011 & 2012 & 2013 & 2014 \\
\hline Española & 86,5 & 84,3 & 82,0 & 80,9 & 81,1 & 81,8 & 82,1 & 81,7 & 83,5 & 83,5 \\
\hline $\begin{array}{l}\text { Española y doble } \\
\text { nacionalidad }\end{array}$ & 0,6 & 0,7 & 0,8 & 0,9 & 1,1 & 1,5 & 1,8 & 1,8 & 2,2 & 2,6 \\
\hline Extranjera & 12,9 & 15,0 & 17,2 & 18,2 & 17,8 & 16,8 & 16,1 & 16,5 & 14,3 & 13,9 \\
\hline Total & 100 & 100 & 100 & 100 & 100 & 100 & 100 & 100 & 100 & 100 \\
\hline
\end{tabular}

Tabla 5 - Jóvenes por nacionalidad (\%). España, 2005-2014

\section{Los jóvenes etiquetados como NINI}

El concepto NINI es el acrónimo de 'Ni estudia, Ni trabaja', que proviene de la expresión anglosajona NEET ('Not in Education, Employment or Training'). Este concepto se utiliza por primera vez en Reino Unido en 1999 en el informe "Bridging the Gap: New Opportunities for 16-18 Year Olds Not In Education, Employment Or Training" (Social Exclusion Unit, 1999). En el año 2006, la Organización Internacional del Trabajo incorpora este indicador en una de sus publicaciones. Y en 2007 la Dirección General de Empleo, Asuntos 
Sociales e lgualdad de Oportunidades de la Comisión Europea, en su informe anual sobre empleo en Europa, presenta datos sobre los NINI. En 2010 la Comisión Europea establece la monitorización de la situación de los jóvenes $\mathrm{NINI}$ en las bases de datos de la Unión Europea. Y, en 2011, Eurostat, gracias al acuerdo de los estados miembros, suscribe la siguiente definición de NINI: población desocupada e inactiva que no cursa ningún tipo de estudio, y se aplica a las personas jóvenes de entre 15 y 34 años (Serracant, 2012, pp. 2123).

Hay bastante controversia sobre este concepto, sobre todo por el sentido impuesto por los medios de comunicación, los cuales han extrapolado las condiciones sociales y personales extremas de una minoría de jóvenes a toda una generación. Es un indicador que no resuelve ciertos problemas, como el de su heterogeneidad, ya que su propio diseño trasciende el objetivo inicial del mismo, que es identificar trayectorias sociales de exclusión social que son propias de un sujeto que actúa pasivamente ante el mundo del trabajo y de los estudios. Incluso dentro de su operacionalización se incluyen colectivos que van desde los vulnerables hasta los que disfrutan de un estatus elevado. Olvida otros colectivos que podrían estar dentro de esta categoría, pero que por su condición - por ejemplo, parado de larga duración - quedan fuera. También considera incluida la situación de 'inactivo' y no estar estudiando, o la situación de los parados de larga duración que no realizan ningún tipo de formación, aunque esto no sea un hecho exclusivo de la juventud. Y, sin embargo, estos colectivos están más afectados social, política y económicamente a consecuencia de la ausencia de una protección social y familiar, que sí posee la mayoría de los jóvenes. Por último, este concepto tiene el inconveniente de que ha conseguido individualizar y estigmatizar a aquellos que caen dentro de ese paraguas (Serracant, 2012, pp. 23-26).

Es relevante subrayar que tanto la opinión pública como la opinión publicada han definido a los NINI como una 'generación perdida', como sujetos carentes de interés o motivación por lo que les rodea, o por su porvenir. Se les tacha de estar anclados en la satisfacción inmediata, en el hoy; de no hacer planes, de ser apáticos, o indolentes - por lo que a los medios les ha resultado rápida y fácilmente identificarlos como culpables, a cada uno de ellos, de esta aparente actitud desdeñosa. No es de extrañar, ya que se ha generalizado en parte de la sociedad, un discurso que convierte 
fácilmente a estos individuos en los únicos responsables de su situación. Se les acusa de no haber aprovechado las oportunidades que ofrece el sistema. Su inacción es producto de la carencia de una actitud positiva y activa. Culpabilizar en exclusiva a los jóvenes es olvidar que los individuos son, parafraseando a Ortega y Gasset, ellos y sus circunstancias; es decir, éstos viven en un entorno social con unas oportunidades y unas limitaciones que influyen en sus éxitos o fracasos futuros. Como ya dijera Coleman en su informe solicitado por el Presidente del Congreso de los Estados Unidos en 1966, y trasladando la idea al tema que nos ocupa, el hándicap del joven sin estudios obligatorios terminados, incluso de cualquier otro, no es únicamente que debe hacer frente a sus propios problemas socioeconómicos de su hogar, sino que está rodeado de gente con las mismas desventajas, que más que animarlo hacia un mejor desempeño académicos le hace ser más pesimista acerca de su futuro (Coleman, 1966). O cómo Bourdieu y Martín Criado, en su libro Cuestiones de Sociología (2003, pp. 21-22), en defensa del papel científico de la sociología, ejemplificaban una correlación entre el éxito escolar, que se identifica con la inteligencia, y el origen social, o, para ser más exactos, el capital cultural heredado de la familia. Pero más allá de esto, también las circunstancias socioeconómicas han propiciado o han alentado el incremento de este colectivo, en la medida en que el mercado laboral era especialmente atractivo para los jóvenes que se veían frustrados por el propio modelo educativo.

Pero la realidad es más compleja que este simple imaginario social sobre un grupo de jóvenes que por circunstancias han abandonado los estudios y no trabajan. En la actualidad, el 51,7\% de los jóvenes entre los 15 y 29 años no trabajan ni están incorporados al sistema educativo ni formativo, $26 \%$ de los hombres y el 25,7\% de las mujeres (Ministerio de Educación, Cultura y Deporte [MECD], 2015). Estos jóvenes sin estudios y que además no trabajan en 2005 representaban el 34\%, contra el 25\% de jóvenes varones activos y el 48,3\% de las jóvenes mujeres activas. Entre 2005 y 2014 se produjo un incremento de más del doble de jóvenes sin estudios obligatorios terminados que además no trabajaban, y si bien este aumento no fue tan grande en el caso de las mujeres, es el más significativo en términos globales, en la medida en que en 2005 casi la mitad de las mujeres se encontraban en esta situación y, en 2014 , se incrementa hasta el $63,4 \%$, aunque el punto 
álgido lo encontramos en 2012, con un 65,5\% de mujeres jóvenes sin estudios que además no trabajaban - pero obviamente no son las mismas circunstancias que antes de la crisis (Tabla 6).

\begin{tabular}{|l|c|c|c|c|c|c|c|c|c|c|}
\hline & 2005 & 2006 & 2007 & 2008 & 2009 & 2010 & 2011 & 2012 & 2013 & 2014 \\
\hline Hombre & 25,0 & 25,7 & 49,1 & 49,2 & 26,4 & 40,8 & 51,5 & 56,8 & 56,7 & 54,4 \\
\hline Mujer & 48,3 & 46,2 & 55,5 & 57,4 & 46,5 & 50,7 & 59,7 & 65,5 & 61,6 & 63,4 \\
\hline Total & 34,0 & 33,6 & 51,6 & 52,5 & 34,4 & 44,6 & 54,8 & 60,3 & 58,7 & 58,1 \\
\hline
\end{tabular}
[Fuente: INE, www.ing EPA. Elaboración propia]

Tabla 6 - Jóvenes sin estudios obligatorios terminados que no cursan ningún tipo de estudios (ni reglados, ni no reglados) y que no trabajan, por sexo (\% horizontal). España, 2005-2014

Cabe también destacar un año que rompe la línea de tendencia de este incremento del porcentaje de NINI en este período, que es el año 2009. Como se puede ver, se produjo un rápido e intenso descenso, pero breve, de las tasas de paro de estos jóvenes, que afectó más a los hombres que a las mujeres, y que tiene su raíz en el impacto que tuvo sobre el empleo el Plan Español para el Estímulo de la Economía y del Empleo: Plan E, establecido por Real Decreto-Ley 9/2008, del mes de noviembre. Y del que se esperaba "tanto por el volumen de fondos que se movilizan, 11.000 millones de euros, como por la capilaridad de las actuaciones que se pondrán en marcha, que generarán 300.000 empleos distribuidos por toda la geografía española". Se calcula que se generaron 422.700 puestos de trabajo (Seminari d'Economia Crítica Taifa, 2010, pp. 68-69).

Otro hecho a destacar se refiere al cambio en el perfil de género de los NINI. Como veíamos antes, el perfil de los jóvenes sin estudios obligatorios terminados es eminentemente masculino; sin embargo, en el caso de los NINI podemos observar que es, al comienzo del período analizado, mayoritariamente femenino y que lentamente ha ido cambiando hacia un mayor peso de los jóvenes varones, a medida que se fue agudizando la crisis (Tabla 7). Esto de algún modo demuestra que una parte de los NINI lo son por la coyuntura. Es decir, en época de bonanza económica los jóvenes - y especialmente los hombres - abandonaban los estudios para incorporarse 
como mano de obra poco cualificada a un mercado laboral marcado por la construcción y sus empresas afines; una vez estallada la burbuja inmobiliaria, éstos jóvenes son expulsados del mercado y tienden a engrosar la lista de NINI.

\begin{tabular}{|l|c|c|c|c|c|c|c|c|c|c|}
\hline & 2005 & 2006 & 2007 & 2008 & 2009 & 2010 & 2011 & 2012 & 2013 & 2014 \\
\hline Hombre & 45,3 & 47,2 & 57,9 & 55,8 & 46,2 & 56,4 & 56,2 & 55,6 & 57,2 & 55,2 \\
\hline Mujer & 54,7 & 52,8 & 42,1 & 44,2 & 53,8 & 43,6 & 43,8 & 44,4 & 42,8 & 44,8 \\
\hline Total & 100 & 100 & 100 & 100 & 100 & 100 & 100 & 100 & 100 & 100 \\
\hline
\end{tabular}

Tabla 7 - Jóvenes sin estudios obligatorios terminados que no cursan ningún tipo de estudios (ni reglados, ni no reglados) y que no trabajan, por sexo (\% vertical). España, 2005-2014

¿Cómo demostramos este hecho? Pues a través del porcentaje de jóvenes sin estudios obligatorios terminados ocupados por tipo de actividad y ocupación principal (ver Tablas A1 y A2 del Anexo). Tal y como se observa en las tablas, se ha producido un significativo descenso en el porcentaje de jóvenes varones sin estudios que trabajaban en la construcción entre 2005 y 2014. Hemos pasado de un $36,7 \%$ a un $12,4 \%$. Se ha reducido en tres veces el porcentaje de este colectivo en este sector de actividad, que en parte ha sido absorbido por el sector del comercio. También podemos observar cómo se ha producido un descenso según el tipo de actividad principal, especialmente en el caso de los varones, en el porcentaje de artesanos y trabajadores cualificados, pasando de un $37,6 \%$ a un $24,3 \%$. Dicho de otro modo, se ha producido una reducción de un tercio en el período de análisis. En el caso de las mujeres, las tasas en los sectores de ocupación y de actividad no se han visto modificadas sustancialmente, a causa de que sus ocupaciones y tipo de actividad tienen un comportamiento anticíclico (Frutos Balibrea, 2008).

Se ha producido una significativa transformación en el porcentaje de jóvenes que realizan estudios o se están formando desde el inicio de la crisis. En la siguiente tabla se analiza la evolución del nivel de participación en la educación formal y no formal (Tabla 8). Entre el grupo de edad de 15-24 se 
puede observar cómo a partir del año 2008 se incrementa en 12,1 puntos el porcentaje de población joven que realiza educación y formación formal o no formal, produciendo una intensificación del fenómeno respecto al periodo comprendido entre 2005 y 2008, dónde únicamente se incrementó un 1,1\%.

\begin{tabular}{|l|c|c|c|c|c|c|c|c|c|c|}
\hline & 2005 & 2006 & 2007 & 2008 & 2009 & 2010 & 2011 & 2012 & 2013 & 2014 \\
\hline Educ. y Form. & 58,3 & 58,7 & 59,0 & 59,4 & 61,6 & 64,5 & 66,1 & 68,5 & 70,0 & 71,5 \\
\hline Ni Educ. Ni Form. & 41,7 & 41,3 & 41,0 & 40,6 & 38,4 & 35,5 & 33,9 & 31,5 & 30,0 & 28,5 \\
\hline Total & 100 & 100 & 100 & 100 & 100 & 100 & 100 & 100 & 100 & 100 \\
\hline
\end{tabular}

Tabla 8 - Jóvenes de entre 15 y 24 años según realicen estudios 0 formación (\%). España, 2005-2014

Sin embargo, no podemos dejar de destacar lo coyuntural de este fenómeno. Como se puede apreciar en la siguiente gráfica (Gráfico 4), el incremento de jóvenes que están estudiando acompaña al inicio de la crisis económica junto al aumento del desempleo. De este modo, a partir del año 2008 el porcentaje de jóvenes desempleados que se están formando han ascendido del $49,7 \%$ al $66,1 \%$ en 2014 . Igualmente, se destaca el grupo de personas que se encuentra trabajando y que no realiza una actividad educativa o formativa, la cual ha descendido desde 2008 del $26,3 \%$ al $11,3 \%$ en 2014. Las personas desempleadas que no realizan algún tipo de formación permanecen estables $y$, al mismo tiempo, se ha reducido ligeramente el grupo de jóvenes que se encuentran empleados y se están formando. 


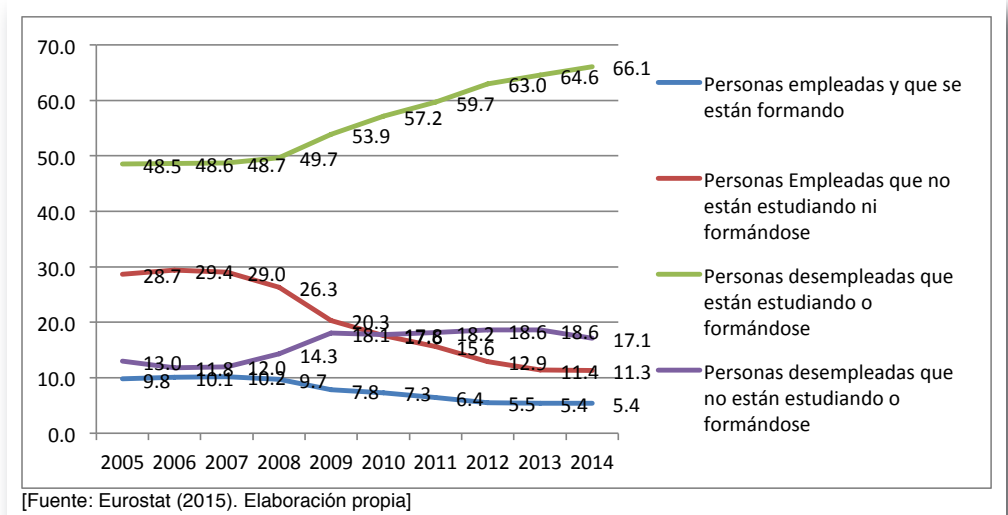

Gráfico 4 - Formación de los jóvenes según su vinculación con el mercado de trabajo

Si bien las nuevas exigencias del mercado de trabajo muestran una mayor tendencia a continuar en el sistema educativo, la cada vez mayor exigencia profesional y, por tanto, la demanda de formación, alarga la estancia en el sistema educativo, incluso en los niveles superiores donde, al mismo tiempo, se reduce el número de becas, se limita la investigación o se suprimen los intercambios (OECD, 2011).

\section{Condiciones de trabajo de los jóvenes sin estudios obligatorios terminados}

Ahora cabe interrogarnos sobre las condiciones de trabajo de la población joven en general y sin estudios obligatorios terminados, y, como podemos observar, la porcentaje de contratos temporales de los jóvenes sin estudios ha permanecido relativamente constante. Es interesante destacar dos aspectos: primero que la reforma laboral de 2012 no ha supuesto una reducción del porcentaje de contratos temporales, sino todo lo contrario: en el caso de los hombres se ha producido un incremento de cuatro puntos porcentuales, y en el de las mujeres de casi siete. Y, en segundo lugar, que el período de bonanza económica no se caracterizó, como cabría suponer, por 
mantener porcentajes bajos de temporalidad en el empleo de los jóvenes sin estudios. Habría que preguntarse si este hecho es consecuencia de su condición de baja escolaridad, "sin estudios", o es debido a la propia estructura productiva vigente en dicho período.

No podemos olvidar las disparidades entre hombres y mujeres. Como podemos ver en la tabla 9, por un lado, la formación supone un elemento compensador de las desigualdades de género en el acceso al mercado laboral, ya que, conforme aumenta el nivel formativo, la diferencia por sexo es de 17 puntos porcentuales para los que no han alcanzado la segunda etapa de Secundaria y de 7 para los que tienen Educación Terciaria (MECD, 2015, p. 8). Por otro lado, el hecho de que los contratos temporales en 2005 fueran de un $58 \%$ podría indicarnos que los hombres son castigados por el mercado por su escasa cualificación. Un ejemplo palpable es el de trabajadores del segmento secundario de empleo caracterizado por ofrecer trabajos inestables, mal considerados, de baja retribución, malas condiciones laborales y escasas posibilidades de promoción (Piore, 1983), agravadas por la imposibilidad de encontrar alternativas públicas para mejorar su cualificación formal.

La temporalidad en el empleo de los jóvenes de entre 16 y 29 años es muy elevada y se mantiene prácticamente estable en la última década. Sin embargo, hay que resaltar que desde el 2005 hasta el 2010 experimentó una reducción hasta el $44,6 \%$, en parte como consecuencia del inicio de la crisis económica y la destrucción de mano de obra, especialmente en el sector de la construcción. En el caso de los contratos de media jornada, en la última década han experimentado un crecimiento, llegando casi a duplicarse, mientras que en el año 2005 representaban el 15,1\%, mostrando un crecimiento lineal hasta alcanzar el 27,5\% en 2014 (Eurostat, 2015).

\begin{tabular}{|l|c|c|c|c|c|c|c|c|c|c|}
\cline { 2 - 11 } \multicolumn{1}{c|}{} & 2005 & 2006 & 2007 & 2008 & 2009 & 2010 & 2011 & 2012 & 2013 & 2014 \\
\hline Hombre & 58,6 & 57,2 & 55,9 & 47,9 & 47,4 & 46,9 & 47,8 & 48,4 & 50,2 & 52,8 \\
\hline Mujer & 56,7 & 55,9 & 49,9 & 47,3 & 42,8 & 40,8 & 43,2 & 42,6 & 47,4 & 49,4 \\
\hline Total & 58,0 & 56,8 & 53,9 & 47,7 & 45,6 & 44,6 & 46,1 & 46,3 & 49,1 & 51,5 \\
\hline
\end{tabular}
[Fuente: INE, www.ine.es EPA. Elaboración propia]

Tabla 9 - Evolución de la proporción de jóvenes sin estudios obligatorios terminados contratados de forma temporal, según sexo (\%). España, 2005-2014 
Por lo que se refiere a los tipos de contrato o su relación laboral de carácter temporal (ver tabla A3 en el Anexo), la mayoría de ellos, con valores que oscilan entre uno de cada cinco y la mitad de los mismos, son por obra y servicio, seguido por circunstancias de la producción y estacional o de temporada, esta última especialmente en el caso de las mujeres - hecho que concuerda con el tipo de sector servicios en el que trabajan. Mayoritariamente, los jóvenes no perciben un desfase subjetivo entre la educación y los requerimientos del puesto de trabajo, ya que el $70 \%$ de los jóvenes considera que es razonable y sólo un $26 \%$ de ellos considera que realiza un trabajo que está por debajo de su cualificación (Instituto Valenciano de Investigaciones Económicas [IVIE], 2013).

Por último, vemos en la siguiente tabla (Tabla 10), referida a la duración del contrato de los jóvenes sin estudios obligatorios terminados, que los jóvenes de ambos sexos, y especialmente los varones, presentan porcentajes muy altos con contratos de menos de un mes de duración. Con la entrada de la reforma laboral de 2012 la extensión de este tipo de contrato de corta duración se ha extendido para ambos sexos: más del $80 \%$ - en casi todos los años han tenido contratos con una duración igual o menor de seis meses. Ello demuestra la difícil tarea de crear un proyecto de vida que la posesión de formación podría mejorar, pero si además se añaden los proyectos de flexibilización laboral de los distintos gobiernos, así como las imposiciones neoliberales en materia de empleo de la UE y la delicada coyuntura económica, supone un empeoramiento de tales condiciones. 


\begin{tabular}{|c|c|c|c|c|c|c|c|c|c|c|c|}
\hline & & 2005 & 2006 & 2007 & 2008 & 2009 & 2010 & 2011 & 2012 & 2013 & 2014 \\
\hline \multirow{8}{*}{$\begin{array}{l}\text { ֻ } \\
\text { है } \\
\text { 오 }\end{array}$} & Menos de un mes & 36,3 & 43,3 & 46,8 & 42,4 & 50,2 & 48,7 & 40,3 & 46,5 & 44,1 & 45,7 \\
\hline & 1 a 3 meses & 17,1 & 16,0 & 16,7 & 16,8 & 16,8 & 17,4 & 20,5 & 18,3 & 19,6 & 17,5 \\
\hline & 4 a 6 meses & 27,5 & 22,3 & 21,1 & 20,5 & 16,4 & 18,5 & 23,8 & 17,7 & 18,3 & 19,0 \\
\hline & 6 a 12 meses & 13,1 & 13,1 & 10,7 & 14,1 & 10,2 & 10,4 & 10,8 & 12,6 & 12,1 & 12,7 \\
\hline & 13 a 24 meses & 3,6 & 2,2 & 2,3 & 2,9 & 3,4 & 2,7 & 2,6 & 2,8 & 1,1 & 1,2 \\
\hline & 25 a 32 meses & 1,9 & 2,3 & 1,9 & 1,8 & 1,7 & 1,5 & 0,9 & 0,8 & 1,6 & 0,5 \\
\hline & Más de 3 años & 0,6 & 0,8 & 0,5 & 1,4 & 1,3 & 0,7 & 1,1 & 1,2 & 3,2 & 3,4 \\
\hline & Total & 100 & 100 & 100 & 100 & 100 & 100 & 100 & 100 & 100 & 100 \\
\hline \multirow{8}{*}{$\frac{\bar{d}}{\frac{\bar{\omega}}{\vec{j}}}$} & Menos de un mes & 27,1 & 29,4 & 30,1 & 34,6 & 36,0 & 36,5 & 36,1 & 31,8 & 48,1 & 38,6 \\
\hline & 1 a 3 meses & 24,7 & 27,4 & 26,3 & 22,1 & 19,2 & 25,6 & 22,9 & 29,7 & 17,9 & 19,2 \\
\hline & 4 a 6 meses & 28,3 & 26,1 & 28,3 & 25,3 & 26,1 & 22,1 & 25,7 & 21,9 & 14,0 & 20,7 \\
\hline & 6 a 12 meses & 14,2 & 13,9 & 11,3 & 14,3 & 12,2 & 11,3 & 14,6 & 14,3 & 15,7 & 15,2 \\
\hline & 13 a 24 meses & 1,7 & 2,1 & 2,0 & 2,5 & 3,7 & 2,4 &, 5 & 8 & 6 & 3,1 \\
\hline & 25 a 32 meses & 1,7 & 0,9 & 1,1 & 0,8 & 1,3 & 0,6 & 0,2 & 1,1 & 0,7 & 0,7 \\
\hline & Más de 3 años & 2,3 & 0,2 & 0,9 & 0,3 & 1,4 & 1,4 & 0,0 & 0,4 & 2,9 & 2,4 \\
\hline & Total & 100 & 100 & 100 & 100 & 100 & 100 & 100 & 100 & 100 & 100 \\
\hline \multirow{8}{*}{$\begin{array}{l}\bar{\Xi} \\
\text { ㅁ }\end{array}$} & Menos de un mes & 33,2 & 38,7 & 41,5 & 39,7 & 45,1 & 44,4 & 38,9 & 41,4 & 45,7 & 43,1 \\
\hline & 1 a 3 meses & 19,6 & 19,8 & 19,7 & 18,6 & 17,7 & 20,4 & 21,4 & 22,3 & 18,9 & 18,1 \\
\hline & 4 a 6 meses & 27,8 & 23,5 & 23,4 & 22,2 & 19,8 & 19,8 & 24,4 & 19,1 & 16,6 & 19,6 \\
\hline & 6 a 12 meses & 13,5 & 13,3 & 10,9 & 14,2 & 10,9 & 10,7 & 12,1 & 13,2 & 13,6 & 13,6 \\
\hline & 13 a 24 meses & 3,0 & 2,2 & 2,2 & 2,8 & 3,5 & 2,6 & 1,8 & 2,1 & 0,9 & 1,9 \\
\hline & 25 a 32 meses & 1,8 & 1,8 & 1,7 & 1,5 & 1,6 & 1,2 & 0,6 & 0,9 & 1,2 & 0,6 \\
\hline & Más de 3 años & 1,2 & 0,6 & 0,7 & 1,0 & 1,3 & 1,0 & 0,7 & 0,9 & 3,1 & 3,0 \\
\hline & Total & 100 & 100 & 100 & 100 & 100 & 100 & 100 & 100 & 100 & 100 \\
\hline
\end{tabular}

Tabla 10 - Evolución de la proporción de jóvenes sin estudios obligatorios terminados contratados temporalmente por meses, según sexo (\%). España, 2005-2014

Los jóvenes, especialmente aquéllos con menor nivel educativo y formativo, se caracterizan por acceder al mercado de trabajo con unas condiciones laborales muy peculiares: alta precariedad laboral, jornadas de trabajo a tiempo parcial, salarios bajos, flexibilidad laboral, desempleo de larga duración, subempleo y subcontratación como consecuencia de la reforma laboral, etc. Estas condiciones laborales propician que se desarrolle una identidad de clase asociada a una alta vulnerabilidad social, incorporándose a los working poor. Los trabajadores pobres jóvenes, como subclase, son "aquellos a quienes los plenamente integrados en la sociedad no necesitan, son bien no ciudadanos, bien no ya ciudadanos, bien no ya plenamente ciudadanos, bien aún no ciudadanos" (Dahrendorf, 1994, p. 13).

La situación actual que viven los jóvenes constriñe su capacidad de autonomía personal, como consecuencia de una agudización de los 
desequilibrios del sistema capitalista, que se desarrolla en un tiempo y espacio en el que conviven dos generaciones juveniles formadas por aquellos que más formación tienen junto con los que carecen de una educación y formación mínima. Esta situación se vincula al aumento del paro de larga duración y, en el caso de acceder al mercado de trabajo, a los contratos precarios. Quizá esta sea una de las razones por las cuales sólo el 53,76\% de los jóvenes prefiere trabajar a recibir subsidios, independiente del trabajo. Un $31,47 \%$ varía según el tipo de trabajo y, en el lado opuesto, un 14,77\% prefiere recibir un subsidio a trabajar (IVIE, 2013).

En este sentido, las personas que abandonan los estudios se caracterizan por una peor empleabilidad: participan menos en el mercado de trabajo, tienen una menor probabilidad de empleo, están más expuestos a la temporalidad y obtienen menores salarios, reflejo de su menor productividad. Así, el abandono escolar es un factor potenciador no solo de situaciones presentes de dificultad social, sino también de futuras, ya que,

"los estudiantes que abandonan el sistema educativo sin una educación secundaria superior se enfrentan a graves dificultades para entrar y permanecer en el mercado de trabajo, sufriendo salarios más bajos, mayor riesgo de pobreza, y mayores posibilidades de convertirse en una carga económica y social para la sociedad" (OECD, 2013, p. 46).

De este modo, el abandono escolar y sus efectos no pueden entenderse desde una óptica personal, dado que, si incide en la productividad de un país, redunda en el bienestar del conjunto de ciudadanos y, por tanto, tiene consecuencias sociales.

\section{A modo de conclusión...}

El futuro se presenta sumamente incierto para los jóvenes sin estudios obligatorios completos. La mayor parte de los puestos de trabajo que se crean son temporales, a tiempo parcial y mal pagados. $Y$ los que no encuentran empleo se van quedando cada vez más alejados de la 'normalidad', puesto que se les acaba todo tipo de protección de seguro, pensado para épocas de crisis más cortas que la actual. Mientras estos hechos sociales ocurren, las políticas educativas siguen con un relato de corte individual basado en la elección racional sin considerar la desigualdad estructural previa a las decisiones de seguir o no estudiando. 
Las condiciones laborales de los jóvenes sin estudios obligatorios completos son cada vez más precarias e inseguras, y además con menos oportunidades de futuro, ya que el nuevo modelo educativo pretende limitar el acceso a la formación superior, en contra de dictámenes y opiniones generales de especialistas en educación que consideran que la única vía de mejora sostenible del crecimiento económico y del progreso social debe ir de la mano de la expansión de su sistema de educación terciaria, al tiempo que se trabaje en la reducción de la tasa de población joven con niveles educativos bajos. Obviar la importancia de este colectivo dejándolo sin protección educativa frente a los riesgos de desempleo, precariedad laboral y exclusión social podría derivar en una pérdida de los avances alcanzados en España gracias a la hasta ahora alta rentabilidad educativa de la población con estudios superiores.

Algunos ejemplos importantes de esta situación tan precaria los encontramos en la tasa de paro de este colectivo de jóvenes, que ha oscilado entre el $34 \%$ en 2005 y el $60,3 \%$ en 2012 . O cómo más de la mitad de ellos se emplean entre la construcción, el comercio o la hostelería; o como la gran mayoría realiza trabajos en el segmento secundario del empleo, caracterizado por ofrecer trabajos inestables, mal considerados, de baja retribución, malas condiciones laborales y escasas posibilidades de promoción, todo ello aderezado con la imposibilidad de encontrar alternativas públicas para mejorar su cualificación formal. O cómo la supuesta reducción del porcentaje de jóvenes sin estudios obligatorios completos no se haya debido a políticas activas de inclusión escolar o compensación de los déficits sociales y educativos, sino a una mera cuestión de envejecimiento demográfico.

Hablamos de crisis de oportunidades porque entendemos que el modelo de igualdad de oportunidades ha quebrado. El proceso de privatización del sistema educativo, que se inició a mediados de la década de los años noventa, ha conseguido polarizar la pirámide educativa española, hasta el extremo de que, hoy, España es el único país de la OCDE en el que se da un modelo dual: altas tasas tanto de jóvenes con educación superior como jóvenes con un nivel educativo bajo. El $41,1 \%$ de jóvenes entre 25 y 34 años han alcanzado el nivel educativo terciario y el $34,9 \%$ de los individuos de esta edad no tienen una cualificación de secundaria superior. Si a esto le unimos una estructura productiva que usa intensivamente mano de obra poco 
cualificada, y un mercado laboral extremadamente flexible en materia de contratación, lo que nos encontramos es que los jóvenes en general, pero especialmente los jóvenes sin estudios (si las instituciones públicas no lo remedian con políticas activas de formación y empleo), engrosarán con mucha facilidad las filas de una gran bolsa de ciudadanos vulnerables social, laboral y económicamente.

¿Por qué una crisis de las oportunidades? Porque todos los avances e hitos históricos en la educación conseguidos durante la España democrática son hoy casi papel mojado. Es verdad que hemos conseguido que la gran mayoría de las clases medias acepten y consideren positiva la inversión en educación, incluso que los propios jóvenes y estudiantes conciban estudiar como algo necesario para mejorar sus condiciones de vida. Al mismo tiempo, la educación se ha mercantilizado, financiado la segregación educativa por clase, y en algunos casos por sexo. Hemos diseñado leyes que fomentan la distinción entre los que saben y pueden y los que no saben ni pueden. Hemos criminalizado el fracaso, responsabilizado de dicho fracaso al sujeto en exclusiva, olvidando los contextos sociales, y hemos perdido la oportunidad de aprovechar los recursos. En suma, hemos hecho real la crisis de las oportunidades.

\section{Notas}

1 El tiempo recorrido y el tiempo por recorrer hacia el futuro en términos de probabilidad, a partir de las elecciones y los determinantes del tiempo presente.

2 El espacio resultante presenta, a juicio de Casal, García, Merino, y Quesada (2007), seis grandes itinerarios-trayectorias: a) de Éxito precoz: con titulaciones altas e inserciones con proyección de futuro; b) Trayectorias obreras: con formación corta pero con un techo muy definido y corto de calificación profesional; c) Trayectorias de adscripción familiar: se desarrollan en determinados ámbitos de minorías étnicas o en lugares de cultura rural dispersa; d) Trayectorias de aproximación sucesiva: identifican itinerarios de jóvenes que apuntan hacia una inserción con éxito que les demanda toma de decisiones y itinerarios de formación prolongados pero también ciertas demoras o ajustes a las situaciones de estudio y/o trabajo y, finalmente, atrasos en el mismo proceso de emancipación familiar por razones económicas o de estrategia; e) Trayectorias de precariedad: identifican itinerarios de jóvenes con bajos niveles de formación y calificación profesional. La particularidad de estas trayectorias es que estan dominadas por un mercado laboral muy precario: comprende tanto a gente con poca formación como a jóvenes que tienen titulaciones altas pero que han tenido que asumir ajustes a las bajas y escasas 
posibilidades de promoción profesional. La precariedad no viene definida sólo por el tipo de contrato sino por la forma de vulnerabilidad en el trabajo (riesgo de paro y poca acumulación profesional); f) Trayectorias erráticas o de bloqueo: identifican itinerarios de jóvenes que por razones diversas quedan durante muchos años fuera de los circuitos de la formación y del trabajo. En todo caso los ingresos provienen de tareas de economía no legalizada. El paro crónico y la baja posibilidad de estar ocupados tienden a hacerse continuos o permanentes. Las modalidades de transición a la vida adulta, sin embargo, son históricas y cambiantes. En el marco del capitalismo informacional están sujetas a un proceso de cambio en varias direcciones: en primer lugar, el receso del éxito precoz de las trayectorias obreras y de la adscripción familiar; en segundo lugar, la aproximación sucesiva adquiere más dominio porque implica a muchos jóvenes (de clases medias pero también de clases populares); en tercer lugar, las trayectorias en precariedad y desestructuración adquieren carácter de emergencia social porque implican también a muchos jóvenes (también de diferentes posiciones sociales), sobre todo ubicados en itinerarios de inserción laboral a la baja y teniendo que diferir las opciones de emancipación familiar.

3 Datos de población extraídos de los cuartos trimestres de cada año.

4 Es interesante destacar que, en términos absolutos, es a partir de 2010 cuando hay más mujeres extranjeras que hombres extranjeros sin estudios. Obviamente, no podemos afirmar con rotundidad que este perfil es una constante, sino que se está manifestando una potencial tendencia agravada aún más por el hecho de que los jóvenes varones extranjeros son numéricamente mayoritarios en los grupos de edad jóvenes.

\section{Referências}

Allerbeck, K., \& Rosenmayr, L. (1979). Introducción a la sociología de la juventud. Buenos Aires: Kapelusz.

Alonso L. E., Martín Criado, E., \& Moreno Pestaña, J. L. (Eds) (2004). Pierre Bourdieu, las herramientas del sociólogo. Madrid: Fundamentos.

Aparicio Fenoll, A. (2010). High-school dropouts and transitory labor market shocks: The case of the Spanish housing boom. IZA Discussion Paper $\mathrm{n}^{\circ} 5139$.

Aparicio, R., \& Portes, A. (2014). Crecer en España: La integración de los hijos de inmigrantes. Barcelona: Fundación "la Caixa".

Baudelot, C., \& Establet, R. (2000). Avoir 30 ans: En 1968 et en 1998. Paris: Seuil.

Beck, U. (1999). Hijos de la libertad. México D. F.: Fondo de la Cultura Económica.

Benedicto, J., \& López, A. (2008). Jóvenes y participación política: Investigaciones europeas. Revista de Estudios de Juventud, 81, 13-28.

Bernardi, F., \& Cebolla, H. (2014). Clase social de origen y rendimiento escolar como predictores de las trayectorias educativas. REIS, 146, 3-22.

Boudon, R. (1983). La desigualdad de oportunidades. La movilidad social en las sociedades industriales. Barcelona: Laia. 
Bourdieu, P., \& Martín Criado, E. (2003). Cuestiones de sociología. Madrid: Itsmo.

Brunet, I., \& Pizzi, A. (2013). La delimitación sociológica de la juventud. Ultima década, 21(38), 11-36.

Casal, J., García, M., Merino, R., \& Quesada, M. (2007). Itinerarios y trayectorias: Una perspectiva de la transición de la escuela al trabajo. Trayectorias: Revista de Ciencias Sociales de la Universidad Nacional de Nuevo León, 22, 9-20.

Casal, J., Merino, R., \& García, M. (2011). Pasado y futuro del estudio sobre la transición de los jóvenes. Papers, 96(4), 1139-1162.

Cavalli, A. G., \& Galland, O. (Dir.) (1993). L'allongement de la jeuneusse. Poitiers: Actes Sud.

Centro de Investigaciones Sociológicas [CIS] (2006). Clases sociales y estructura social. Madrid: CIS, encuesta ${ }^{\circ} 2634$.

Coleman, J. S. (1966). Equality of educational opportunity. Washington, D.C.: U.S. Government Printing Office.

Comisión Europea (2012). Un nuevo concepto de educación: Invertir en las competencias para lograr mejores resultados socioeconómicos. Comunicación de la Comisión al Parlamento Europeo, al Consejo, al Comité Económico y Social Europeo y al Comité de las Regiones, Estrasburgo, 20.11.2012. Disponible en: http://eur-lex.europa.eu/legal-content/ES/TXT/PDF/?uri=CELEX: 52012DC0669\&from $=e s$

Dahrendorf, R. (1994). Ley y orden. Madrid: Civitas.

de Hoyos, R., Halsey, R., \& Székely, M. (2016). Ninis en América Latina. 20 millones de jóvenes en busca de una oportunidad. Washington D.C.: Banco Mundial.

de Zárraga, J. L. (1985). La inserción de los jóvenes en la sociedad. In Informe juventud en España (25). Madrid: Ministerio de Juventud-INJUVE.

Dustmann, C. (2004). Parental background, secondary school track choice, and wages. Oxford Economic Papers, 56(2), 209-230.

Escardibul, J. O., \& Villarroya, A. (2009). The inequalities in school choice in Spain in accordance to PISA data. Journal of Education Policy, 24(6), 673- 696.

Eurostat (2015). Being young in Europe today (2015 ed.). Luxembourg: Office for Official Publications of the European Communities.

Fernández Enguita, M., Mena Martínez, L., \& Riviere Gómez, J. (2010). Fracaso y abandono escolar en España. Barcelona: Fundación "la Caixa".

Fernández, R., \& Muñiz, M. (2012). Colegios concertados y selección de escuela en España: Un círculo vicioso. Presupuesto y Gasto Público, 67, 97-118.

Frutos Balibrea, L. (2008). Situación sociolaboral de mujeres y hombres en la región de Murcia y en España: Una relación asimétrica. Murcia: Consejo Económico y Social.

Frutos Balibrea, L. (2015). Títulos, trabajos y profesiones. In España 2015: Situación social. Madrid: CIS.

Instituto Nacional de Evaluación Educativa (2015). Sistema estatal de indicadores de la educación. 2015. Madrid: Ministerio de Educación, Cultura y Deporte. 
Instituto Valenciano de Investigaciones Económicas [IVIE] (2013). El abandono educativo temprano. Análisis del caso español. Valencia: IVIE.

Jenkins, S., Micklewright, J., \& Schnepf, S. (2006). Social segregation in secondary schools. How does England compare with other countries? IZA Discussion Paper $n^{\circ} 1959$.

Martín Criado, E. (2005). La construcción de los problemas juveniles. Nómadas, 23, 86-93.

Martínez Celorrio, X. (2013). Tendencias de movilidad y reproducción social por la educación en España. RASE, 6, 32-48.

Martínez García, J. S., \& Fernández Mellizo, M. (2015). Desigualdad de oportunidades educativas: Género, clase social y ciudadanía. In España 2015: Situación social. Madrid: CIS.

Ministerio de Educación, Cultura y Deporte [MECD] (2015). Panorama de la educación: Indicadores de la OCDE 2015. Informe español. Madrid: Ministerio de Educación, Cultura y Deporte. Disponible en: http://www.mecd.gob.es/dctm/ inee/internacional/panorama-de-la-educacion-2015.-informe-espanol.pdf? documentld=0901e72b81ee9fa3

OECD (2011). Society at a glance 2011. Paris: OECD Publishing.

OECD (2013). Education at a glance 2013 - OECD Indicators. Paris: OECD Publishing.

Parkin, F. (1984). Marxismo y teoría de clases. Una crítica burguesa. Madrid: Espasa Calpe.

Piore, M. J. (1983). Labor market segmentation: To what paradigm does it belong? The American Economic Review, 73(2), 249-253.

Raftery, A. E., \& Hout, M. (1993). Maximally maintained inequality. Sociology of Education, 66(1), 41-62.

Revilla Castro, J. C. (2001). La construcción discursiva de la juventud. Papers: Revista de Sociologia, 63/64, 103-122.

Salinas, J., \& Santín, D. (2012). Selección escolar y efectos de la inmigración sobre los resultados académicos españoles en PISA 2006. Revista de Educación, 358, 382-405.

Serracant, P. (2012). "Generació NI-NI", estigmatizació i excluió social. Gènesi i evolució d'un concepte problemàtic i proposta d'un nou indicador. Barcelona: G. d. Catalunya Ed.

Serrano, L., Soler, A., Hernández, L., \& Sabater, S. (2013). El abandono educativo temprano: Análisis del caso español [documento de trabajo]. Madrid: INEE.

Social Exclusion Unit (1999). Bridging the gap: New opportunities for 16-18 year olds not in education, employment or training. UK: The Stationery Office.

Solano, J. C. (2008). La exclusión social a través de la desigualdad de oportunidades educativas. In M. H. Pedreño (Coord.), Exclusion social y desigualdad (pp. 105130). Murcia: Ediciones de la Universidad de Murcia.

Seminari d'Economia Crítica Taifa (2010). La crisis en el estado español: El rescate de los poderosos. In: Informes de Economía Crítica, 07. Disponible en: http://informes.seminaritaifa.org/informe-07/

Tezanos, J. F. (2001). El trabajo perdido: ¿Hacia una civilización postlaboral? Madrid: Biblioteca Nueva. 


\section{A CRISE DE OPORTUNIDADES PARA OS JOVENS COM BAIXO NÍVEL DE ESCOLARIDADE EM ESPANHA (2005-2014)}

Resumo

A estrutura educacional da população jovem em Espanha é única em comparação com outros países vizinhos. Caracteriza-se pela polarização do nível de educação dos seus jovens. A Espanha é o único país da OCDE com altas taxas tanto de jovens com educação superior, como de jovens com baixo nível de escolaridade. Questionamo-nos sobre as condições de educação e de trabalho deste grupo de jovens sem escolaridade obrigatória completa que foram duramente atingidos pela crise económica. Precariedade, temporalidade, contratos de formação, contratos a tempo parcial são uma constante no mercado de trabalho espanhol para estes jovens, e estão a tornar-se uma norma informal do acesso ao emprego e a prolongar a precariedade do mesmo; em parte, como resultado de mudanças nas políticas de educação que limitam as suas oportunidades para avanço ou melhoria. A intenção é conhecer, através dos dados do Inquérito ao Emprego, a situação social e laboral dos jovens com poucos estudos em um período muito turbulento: entre o fim do boom económico e a crise económica em Espanha. $E$ interrogamo-nos em que medida as conjunturas socioeconómicas têm acabado com a igualdade de oportunidades, promovendo a construção de uma sociedade dualizada do ponto de vista educacional e do trabalho.

\section{Palavras-chave}

Jovens com baixo nível de escolaridade; Desigualdade de oportunidades; Mercado de trabalho 


\section{EQUAL CHANCES CRISIS FOR YOUNG PEOPLE WITH LOW EDUCATIONAL ATTAINMENT IN SPAIN (2005-2014)}

\section{Abstract}

The educational structure of the young population in Spain is unique compared to other neighbouring countries. It is characterized by the polarization of the levels of education of its young people. Spain is the only country in the OECD with the highest rates of young people with both higher education and low education level. We are considering the educational and working conditions of this part of our society who haven't finished compulsory education and are really punished by the context of the economic crisis. Precariousness, temporality, training contracts or internship and part-time contracts are a constant in the Spanish labour market. They are becoming an informal norm of access to jobs and also a way of prolonged instability about employment. All this is partly due to changes in the educational policies that limit young people's opportunities for promotion or improvement. This article intends to gain insight into the social and occupational situation of young people with low educational attainment in Spain. In order to do so, the Spanish Labour Force Survey will be used, analyzing the period of time ranging from the end of the economic boom from the beginning of the century to the current economic crisis. The research question focuses on the effect of both economic scenarios in the equality of opportunities and to what extent a dual society has emerged both in the educational and occupational realms.

Keywords

Young people with low educational attainment; Inequality of opportunities; Labor market

Recebido em janeiro/2016

Aceite para publicação em maio/2016

i Departamento de Sociología, Facultad de Economía y Empresa, Universidad de Murcia, España.

ii Departamento de Sociología, Facultad de Economía y Empresa, Universidad de Murcia, España.

Toda a correspondência relativa a este artigo deve ser enviada para: Juan Carlos Solano Lucas, Departamento de Sociología, Facultad de Economía y Empresa, Universidad de Murcia, Campus de Espinardo, 30100 Murcia, España. E-mail: jcsolano@um.es 


\section{Anexo}

Tabla A1. Porcentaje de jóvenes sin estudios obligatorios completos, por tipo de ocupación principal y sexo. España, 2005-2014

\begin{tabular}{|c|c|c|c|c|c|c|c|c|c|c|c|c|}
\hline & & 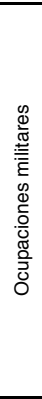 & 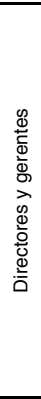 & 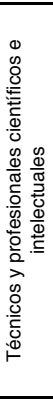 & 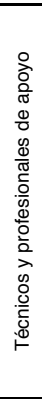 & 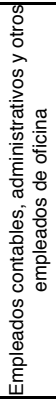 & 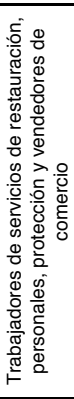 & 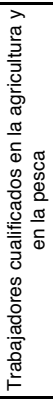 & 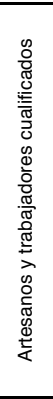 & 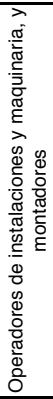 & 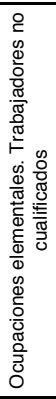 & $\begin{array}{l}\bar{\pi} \\
\text { రँ }\end{array}$ \\
\hline \multirow[t]{10}{*}{ Hombre } & 2005 & 1,0 & 2,4 & 0,1 & 2,5 & 2,5 & 9,2 & 2,9 & 37,6 & 15,8 & 26,1 & 100 \\
\hline & 2006 & 0,9 & 2,2 & 0,1 & 2,3 & 2,7 & 8,9 & 2,5 & 38,3 & 15,4 & 26,7 & 100 \\
\hline & 2007 & 1,2 & 2,0 & 0,1 & 2,1 & 2,9 & 9,1 & 2,3 & 40,6 & 14,8 & 24,9 & 100 \\
\hline & 2008 & 2,1 & 2,0 & 0,2 & 3,1 & 3,3 & 10,9 & 2,7 & 34,5 & 16,8 & 24,4 & 100 \\
\hline & 2009 & 2,3 & 1,9 & 0,3 & 3,4 & 2,6 & 14,1 & 3,0 & 29,0 & 15,6 & 27,7 & 100 \\
\hline & 2010 & 2,7 & 2,3 & 0,0 & 3,8 & 3,5 & 15,2 & 3,3 & 27,0 & 15,6 & 26,5 & 100 \\
\hline & 2011 & 2,5 & 0,7 & 3,4 & & 3,1 & 21,0 & 4,0 & 27,3 & 13,6 & 24,4 & 100 \\
\hline & 2012 & 2,3 & 1,0 & 0,1 & 3,3 & 2,0 & 22,8 & 3,2 & 23,6 & 14,4 & 27,3 & 100 \\
\hline & 2013 & 2,3 & 0,9 & 0,0 & 2,8 & 2,8 & 22,7 & 5,2 & 25,3 & 13,3 & 24,6 & 100 \\
\hline & 2014 & 1,7 & 0,8 & 0,2 & 3,0 & 2,6 & 23,6 & 4,8 & 24,3 & 12,8 & 26,1 & 100 \\
\hline \multirow[t]{10}{*}{ Mujer } & 2005 & 0,8 & 1,8 & 0,1 & 2,8 & 12,0 & 39,5 & 0,7 & 6,7 & 7,6 & 27,9 & 100 \\
\hline & 2006 & 0,6 & 2,0 & 0,1 & 4,0 & 12,2 & 41,0 & 1,1 & 4,3 & 6,3 & 28,4 & 100 \\
\hline & 2007 & 0,3 & 2,4 & 0,0 & 2,6 & 12,4 & 43,8 & 0,7 & 4,8 & 5,8 & 27,1 & 100 \\
\hline & 2008 & 0,3 & 2,1 & 0,1 & 3,1 & 11,6 & 46,6 & 0,5 & 4,1 & 5,5 & 26,0 & 100 \\
\hline & 2009 & 0,7 & 1,9 & 0,1 & 4,0 & 10,9 & 48,2 & 0,9 & 2,9 & 3,7 & 26,7 & 100 \\
\hline & 2010 & 0,9 & 2,3 & 0,1 & 3,1 & 11,8 & 47,6 & 0,8 & 3,2 & 4,7 & 25,4 & 100 \\
\hline & 2011 & 0,6 & 0,3 & 3,4 & & 6,2 & 51,0 & 0,6 & 3,2 & 4,8 & 29,9 & 100 \\
\hline & 2012 & 0,6 & 0,5 & 0,0 & 2,3 & 5,0 & 53,0 & 1,0 & 2,9 & 5,1 & 29,6 & 100 \\
\hline & 2013 & 0,2 & 0,7 & 0,1 & 1,6 & 3,4 & 53,0 & 0,9 & 5,2 & 3,5 & 31,4 & 100 \\
\hline & 2014 & 0,2 & 0,3 & 0,6 & 1,2 & 5,9 & 54,9 & 0,6 & 4,0 & 2,8 & 29,4 & 100 \\
\hline \multirow[t]{10}{*}{ Total } & 2005 & 1,0 & 2,2 & 0,1 & 2,6 & 5,4 & 18,6 & 2,2 & 28,1 & 13,3 & 26,6 & 100 \\
\hline & 2006 & 0,8 & 2,1 & 0,1 & 2,9 & 5,7 & 19,0 & 2,1 & 27,7 & 12,5 & 27,2 & 100 \\
\hline & 2007 & 0,9 & 2,1 & 0,1 & 2,2 & 6,0 & 20,5 & 1,8 & 28,8 & 11,9 & 25,6 & 100 \\
\hline & 2008 & 1,5 & 2,0 & 0,1 & 3,1 & 6,2 & 23,3 & 2,0 & 23,9 & 12,9 & 25,0 & 100 \\
\hline & 2009 & 1,7 & 1,9 & 0,2 & 3,6 & 5,6 & 26,5 & 2,2 & 19,5 & 11,3 & 27,3 & 100 \\
\hline & 2010 & 2,1 & 2,3 & 0,1 & 3,5 & 6,5 & 27,1 & 2,4 & 18,3 & 11,6 & 26,1 & 100 \\
\hline & 2011 & 1,8 & 0,6 & 3,4 & & 4,2 & 31,9 & 2,7 & 18,5 & 10,4 & 26,4 & 100 \\
\hline & 2012 & 1,7 & 0,8 & 0,0 & 2,9 & 3,1 & 33,4 & 2,4 & 16,3 & 11,1 & 28,1 & 100 \\
\hline & 2013 & 1,5 & 0,8 & 0,0 & 2,4 & 3,0 & 34,3 & 3,6 & 17,6 & 9,5 & 27,2 & 100 \\
\hline & 2014 & 1,2 & 0,6 & 0,3 & 2,4 & 3,8 & 34,7 & 3,3 & 17,1 & 9,3 & 27,3 & 100 \\
\hline
\end{tabular}


Tabla A2. Porcentaje de jóvenes sin estudios obligatorios completos, por tipo de actividad principal y sexo. España, 2005-2014

\begin{tabular}{|c|c|c|c|c|c|c|c|c|c|c|c|c|}
\hline & & 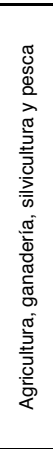 & 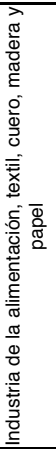 & 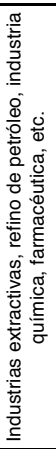 & 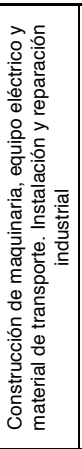 & 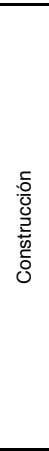 & 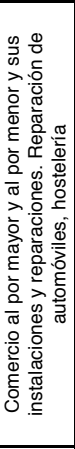 & 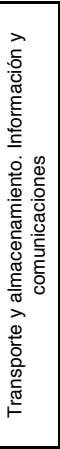 & 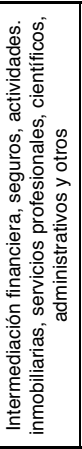 & 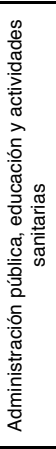 & 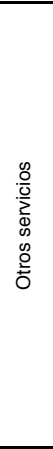 & $\begin{array}{l}\overline{\widetilde{\sigma}} \\
\text { 임 }\end{array}$ \\
\hline \multirow[t]{10}{*}{ Hombre } & 2005 & 6,4 & 6,8 & 10,2 & 6,0 & 36,7 & 20,1 & 5,2 & 3,3 & 2,5 & 2,8 & 100 \\
\hline & 2006 & 7,2 & 4,8 & 10,2 & 6,5 & 37,4 & 20,0 & 4,6 & 4,1 & 2,6 & 2,6 & 100 \\
\hline & 2007 & 5,5 & 5,3 & 9,7 & 5,8 & 39,1 & 20,2 & 5,6 & 3,1 & 3,0 & 2,6 & 100 \\
\hline & 2008 & 6,5 & 6,4 & 10,0 & 6,7 & 28,4 & 23,9 & 6,3 & 4,5 & 4,5 & 2,7 & 100 \\
\hline & 2009 & 8,1 & 5,8 & 8,6 & 5,4 & 23,9 & 26,3 & 7,1 & 5,8 & 6,3 & 2,7 & 100 \\
\hline & 2010 & 10,2 & 6,8 & 8,6 & 4,1 & 20,8 & 28,1 & 6,6 & 6,1 & 5,7 & 3,0 & 100 \\
\hline & 2011 & 10,8 & 5,1 & 8,1 & 5,1 & 16,5 & 31,2 & 6,2 & 6,5 & 7,0 & 3,4 & 100 \\
\hline & 2012 & 12,4 & 7,3 & 7,8 & 4,3 & 11,5 & 35,6 & 6,7 & 5,6 & 5,5 & 3,3 & 100 \\
\hline & 2013 & 14,2 & 7,3 & 6,8 & 4,3 & 11,4 & 33,5 & 6,3 & 5,5 & 6,4 & 4,2 & 100 \\
\hline & 2014 & 12,2 & 8,1 & 6,5 & 4,5 & 12,4 & 35,3 & 6,0 & 5,8 & 5,0 & 4,3 & 100 \\
\hline \multirow[t]{10}{*}{ Mujer } & 2005 & 6,1 & 9,4 & 3,3 & 3,5 & 1,1 & 47,3 & 2,5 & 6,7 & 3,6 & 16,6 & 100 \\
\hline & 2006 & 4,4 & 7,2 & 2,3 & 2,8 & 1,5 & 47,3 & 1,3 & 7,7 & 5,5 & 20,0 & 100 \\
\hline & 2007 & 3,8 & 7,6 & 2,3 & 3,4 & 0,9 & 51,8 & 1,7 & 8,7 & 3,4 & 16,4 & 100 \\
\hline & 2008 & 4,5 & 6,5 & 2,0 & 2,3 & 1,0 & 51,1 & 2,4 & 8,8 & 5,2 & 16,3 & 100 \\
\hline & 2009 & 4,4 & 4,7 & 1,4 & 2,2 & 0,9 & 50,9 & 2,0 & 7,9 & 5,9 & 19,6 & 100 \\
\hline & 2010 & 4,0 & 5,9 & 2,0 & 1,5 & 1,1 & 51,2 & 3,1 & 6,9 & 5,9 & 18,3 & 100 \\
\hline & 2011 & 3,6 & 4,4 & 1,3 & 1,9 & 1,1 & 52,2 & 2,6 & 8,6 & 5,2 & 19,1 & 100 \\
\hline & 2012 & 4,2 & 6,8 & 1,0 & 1,4 & 0,5 & 52,4 & 2,0 & 7,6 & 5,3 & 18,6 & 100 \\
\hline & 2013 & 5,5 & 5,0 & 1,5 & 1,1 & 1,5 & 50,9 & 1,8 & 7,8 & 4,2 & 20,7 & 100 \\
\hline & 2014 & 4,3 & 4,9 & 1,3 & 1,0 & 0,7 & 54,4 & 1,7 & 7,6 & 5,3 & 18,7 & 100 \\
\hline \multirow[t]{10}{*}{ Total } & 2005 & 6,3 & 7,6 & 8,1 & 5,2 & 25,7 & 28,5 & 4,4 & 4,4 & 2,8 & 7,1 & 100 \\
\hline & 2006 & 6,3 & 5,5 & 7,7 & 5,3 & 26,1 & 28,6 & 3,6 & 5,3 & 3,5 & 8,1 & 100 \\
\hline & 2007 & 4,9 & 6,0 & 7,3 & 5,0 & 26,6 & 30,6 & 4,3 & 5,0 & 3,2 & 7,1 & 100 \\
\hline & 2008 & 5,8 & 6,4 & 7,2 & 5,2 & 18,9 & 33,4 & 5,0 & 6,0 & 4,7 & 7,4 & 100 \\
\hline & 2009 & 6,8 & 5,4 & 6,0 & 4,2 & 15,5 & 35,3 & 5,3 & 6,6 & 6,1 & 8,8 & 100 \\
\hline & 2010 & 7,9 & 6,4 & 6,2 & 3,2 & 13,6 & 36,6 & 5,3 & 6,4 & 5,8 & 8,6 & 100 \\
\hline & 2011 & 8,1 & 4,9 & 5,6 & 3,9 & 10,9 & 38,9 & 4,9 & 7,3 & 6,4 & 9,2 & 100 \\
\hline & 2012 & 9,5 & 7,1 & 5,4 & 3,3 & 7,6 & 41,5 & 5,1 & 6,3 & 5,5 & 8,7 & 100 \\
\hline & 2013 & 10,9 & 6,4 & 4,7 & 3,1 & 7,6 & 40,2 & 4,6 & 6,4 & 5,6 & 10,5 & 100 \\
\hline & 2014 & 9,4 & 7,0 & 4,7 & 3,3 & 8,2 & 42,0 & 4,5 & 6,4 & 5,1 & 9,4 & 100 \\
\hline
\end{tabular}


Tabla A3. Porcentaje de jóvenes sin estudios obligatorios completos, por tipo de contrato o relación laboral de carácter temporal y sexo. España, 2005-2014

\begin{tabular}{|c|c|c|c|c|c|c|c|c|c|c|c|}
\hline & & 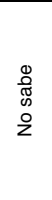 & 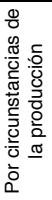 & 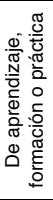 & 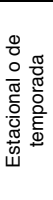 & 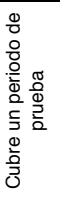 & 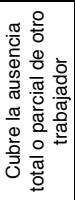 & 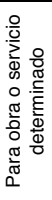 & 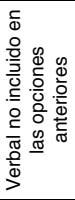 & 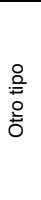 & $\begin{array}{l}\text { त्ञ } \\
\text { ○ }\end{array}$ \\
\hline \multirow[t]{10}{*}{ Hombre } & 2005 & 22,4 & 18,7 & 4,6 & 4,7 & 1,8 & 2,2 & 39,8 & 4,4 & 1,5 & 100 \\
\hline & 2006 & 25,3 & 19,6 & 2,5 & 10,0 & 1,9 & 3,6 & 22,9 & 11,5 & 2,6 & 100 \\
\hline & 2007 & 23,3 & 19,0 & 3,9 & 6,4 & 1,8 & 2,6 & 34,5 & 6,7 & 1,8 & 100 \\
\hline & 2008 & 18,6 & 16,7 & 4,9 & 5,7 & 2,2 & 1,6 & 43,4 & 5,3 & 1,6 & 100 \\
\hline & 2009 & 20,6 & 22,8 & 4,1 & 7,7 & 1,8 & 4,3 & 22,2 & 15,1 & 1,4 & 100 \\
\hline & 2010 & 19,3 & 18,7 & 4,7 & 6,3 & 2,1 & 2,5 & 36,6 & 8,4 & 1,5 & 100 \\
\hline & 2011 & 14,7 & 16,6 & 3,6 & 4,5 & 1,9 & 1,3 & 49,8 & 6,4 & 1,1 & 100 \\
\hline & 2012 & 15,7 & 25,7 & 3,2 & 9,7 & 2,8 & 4,7 & 24,9 & 12,0 & 1,3 & 100 \\
\hline & 2013 & 15,0 & 19,5 & 3,5 & 6,1 & 2,1 & 2,4 & 42,0 & 8,2 & 1,2 & 100 \\
\hline & 2014 & 13,1 & 20,4 & 4,0 & 8,7 & 1,8 & 1,9 & 44,4 & 4,3 & 1,3 & 100 \\
\hline \multirow[t]{10}{*}{ Mujer } & 2005 & 10,5 & 22,2 & 4,2 & 12,9 & 1,0 & 4,4 & 30,4 & 12,0 & 2,5 & 100 \\
\hline & 2006 & 12,2 & 21,0 & 4,1 & 10,2 & 1,5 & 2,8 & 39,4 & 7,0 & 1,7 & 100 \\
\hline & 2007 & 9,6 & 15,9 & 2,6 & 9,3 & 0,8 & 3,9 & 48,5 & 7,0 & 2,3 & 100 \\
\hline & 2008 & 12,4 & 21,1 & 4,0 & 11,1 & 1,1 & 8,8 & 26,1 & 13,5 & 2,1 & 100 \\
\hline & 2009 & 10,6 & 17,7 & 3,1 & 9,9 & 0,9 & 5,6 & 40,6 & 9,3 & 2,3 & 100 \\
\hline & 2010 & 9,8 & 19,4 & 2,9 & 12,1 & 0,9 & 3,0 & 44,8 & 5,6 & 1,5 & 100 \\
\hline & 2011 & 11,8 & 25,1 & 2,8 & 10,8 & 1,5 & 6,5 & 29,8 & 11,2 & 0,4 & 100 \\
\hline & 2012 & 10,5 & 21,4 & 2,8 & 11,7 & 1,1 & 4,2 & 39,6 & 7,5 & 1,1 & 100 \\
\hline & 2013 & 11,8 & 18,5 & 4,2 & 13,6 & 0,8 & 3,4 & 42,8 & 4,1 & 0,6 & 100 \\
\hline & 2014 & 11,0 & 25,0 & 3,4 & 9,4 & 1,1 & 5,6 & 29,3 & 13,5 & 1,6 & 100 \\
\hline \multirow[t]{10}{*}{ Total } & 2005 & 11,6 & 20,8 & 3,9 & 12,1 & 0,9 & 4,2 & 38,1 & 7,4 & 0,9 & 100 \\
\hline & 2006 & 8,1 & 21,4 & 2,1 & 16,3 & 1,8 & 3,4 & 41,5 & 4,4 & 1,0 & 100 \\
\hline & 2007 & 9,6 & 29,1 & 1,7 & 11,1 & 1,4 & 5,5 & 29,6 & 10,6 & 1,3 & 100 \\
\hline & 2008 & 8,6 & 24,0 & 2,0 & 14,6 & 1,7 & 4,1 & 37,5 & 6,5 & 1,1 & 100 \\
\hline & 2009 & 8,0 & 23,6 & 4,4 & 15,5 & 1,3 & 2,9 & 39,0 & 4,2 & 1,1 & 100 \\
\hline & 2010 & 9,0 & 26,2 & 3,8 & 14,1 & 1,2 & 3,5 & 33,6 & 7,7 & 0,8 & 100 \\
\hline & 2011 & 8,4 & 24,6 & 4,2 & 15,0 & 1,3 & 3,1 & 36,9 & 5,6 & 1,0 & 100 \\
\hline & 2012 & 13,8 & 20,3 & 5,1 & 14,1 & 1,4 & 2,5 & 37,6 & 3,8 & 1,3 & 100 \\
\hline & 2013 & 7,8 & 27,6 & 6,5 & 10,2 & 2,2 & 4,3 & 32,5 & 8,2 & 0,7 & 100 \\
\hline & 2014 & 11,7 & 22,9 & 5,6 & 12,8 & 1,7 & 3,1 & 35,8 & 5,4 & 1,1 & 100 \\
\hline
\end{tabular}

[Fuente: INE, www.ine.es EPA. Elaboración propia) 